\title{
Production of Succinoglycan Polymer in Sinorhizobium meliloti Is Affected by SMb21506 and Requires the N-terminal Domain of ExoP
}

\author{
Edgardo Jofré ${ }^{1}$ and Anke Becker ${ }^{2}$ \\ ${ }^{1}$ Departamento de Ciencias Naturales, Facultad de Ciencias Exactas, Físico-Químicas y Naturales, Universidad Nacional \\ de Río Cuarto, Ruta $36 \mathrm{Km} 601$ (X5804BYA) Río Cuarto, Córdoba, Argentina; ${ }^{2}$ Institute of Biology III, Faculty of Biology, \\ University of Freiburg, Schänzlestr 1, 79104 Freiburg, Germany
}

Submitted 26 April 2009. Accepted 10 August 2009.

The protein tyrosine kinase ExoP, consisting of an N-terminal periplasmic and a $\mathrm{C}$-terminal cytoplasmic domain, is important for polymerization of the exopolysaccharide succinoglycan (EPS I) in Sinorhizobium meliloti. We analyzed the contribution of the ExoP paralogs ExoP2 and SMb21506 to the production of the high molecular weight (HMW) form of EPS I. ExoP2, though not contributing to EPS I or lipopolysaccharide biosynthesis, showed increased expression at high osmolarity and was expressed in Medicago sativa nodules, suggesting an involvement in the synthesis of an as-yet-unidentified polysaccharide. Furthermore, a mutation in SMb21506 affected the production of HMW EPS I, particularly in the absence of the C-terminal ExoP domain. High salinity induced the production of HMW EPS I by the wild type and mutants whereas high osmolarity had the opposite effect. It was shown that ExoP localizes at the inner membrane of $S$. meliloti cells. Tyrosine phosphorylation of the $C$-terminal domain was strongly increased by amino acid substitutions in the polysaccharide co-polymerase motif (formerly proline-rich motif) located in the N-terminal domain, suggesting that this phosphorylation could be modulated by conformational changes of the N-terminal domain. Moreover, deletion of a coiled-coil motif present in the $\mathrm{N}$-terminal domain abolished phosphorylation and EPS I production and, consequently, the ability to nodulate $M$. sativa.

Sinorhizobium meliloti produces the exopolysaccharide (EPS) succinoglycan (EPS I) which is required for invasion and development of Medicago sativa root nodules. EPS I is a polymer of octasaccharide repeating units. Each repeating unit contains seven glucose molecules and one galactose molecule joined by $\beta-1,4, \beta-1,3$, and $\beta-1,6$ glycosidic linkages. It can be decorated by acetyl, succinyl, and pyruvyl groups (Aman et al. 1981; Reinhold et al. 1994). Two molecular forms of EPS I have been described, one of high-molecular weight (HMW EPS I) and one of low-molecular weight (LMW EPS I). LMW EPS I consists of monomers, dimers, and trimers of the repetitive octasaccharide subunit. The trimer was identified as the symbiotically active species (Battisti et al. 1992; González et al. 1998; Wang et al. 1999). Although the genes required for EPS I biosynthesis have been described in detail (Skorupska et al. 2006), little is known about polymerization and export of

Corresponding author: E. Jofré; Telephone: +54 (358) 4676438; Fax: +54 (358) 4676230; E-mail address: ejofre@exa.unrc.edu.ar this polysaccharide. Previous studies demonstrated that the membrane-associated proteins ExoQ, ExoT, and ExoP are involved in polymerization and export of EPS I (González et al. 1998). In particular, the $S$. meliloti ExoP protein belonging to the polysaccharide co-polymerase $2 \mathrm{a}$ (PCP2a) family (Morona et al. 2000) is a protein tyrosine kinase (PTK) required for the polymerization or export of EPS I.

The first genetic and biochemical characterization of a PTK in bacteria was reported in Acinetobacter johnsonii (Doublet et al. 1999). Since then, autophosphorylating enzymes exhibiting significant similarities to this PTK have been detected in a large number of gram-negative and gram-positive bacteria. In Escherichia coli, Klebsiella pneumoniae, Streptococcus pneumoniae, Erwinia amylovora, Acinetobacter lwoffii, and Bacillus subtilis, among others, PTK similar to ExoP have been associated with polymerization and secretion of EPS or capsular polysaccharide (CPS), indicating that these PTK and their functions in the polymerization or export of polysaccharides are widely distributed. Another important feature of genes encoding these PTK is their co-localization with genes involved in the biosynthesis of polysaccharides. As for all PTK reported in gram-negative bacteria to date, the Sinorhizobium meliloti ExoP protein can be divided into an $\mathrm{N}$-terminal domain located mainly in the periplasmic space and a $\mathrm{C}$-terminal domain, containing an ATP-binding site (Walker A and Walker B motifs) and tyrosine phosphorylation sites, located in the cytoplasm (Becker et al. 1995; Niemeyer and Becker 2001).

In $S$. meliloti, a knockout mutation of exoP blocked polymerization of EPS I (Gonzaléz et al. 1998). Deletion of only the C-terminal ExoP domain, which displayed ATPase activity when expressed in Escherichia coli (Niemeyer and Becker 2001), resulted in a decreased production of EPS I with an increased ratio of the LMW to the HMW form (Becker et al. 1995). Site-directed mutagenesis of specific tyrosine residues in the C-terminal domain also altered the molecular weight distribution of EPS I (Niemeyer and Becker 2001). Similar results have been observed in E. coli K12 and E. coli K30, where a mutation in Wzc affecting either the ATP-binding sites or specific tyrosine residues resulted in alterations in colanic acid synthesis or capsule assembly, respectively (Wugeditsch et al. 2001; Grangeasse et al. 2002; Paiment et al. 2002; Obadia et al. 2007).

Moreover, the effect of mutations of conserved amino acid residues in the $\mathrm{N}$-terminal domain of the PTK $\mathrm{Wzc}_{\mathrm{ca}}$ and ExoP on polymerization of colanic acid and succinoglycan has been analyzed in E. coli K12 and S. meliloti 2011, respectively. Specific amino acid substitutions in the conserved PCP motif (for- 
merly proline-rich motif) situated in the N-terminal domain of ExoP negatively influenced polymerization of EPS I. In particular, proline P457 and arginine R443 residues were connected with drastic variations in the polymerization of EPS I (Becker and Pühler 1998). In the tyrosine kinase $\mathrm{Wzc}_{\mathrm{ca}}$ of $E$. coli $\mathrm{K} 12$, the presence of this proline residue (P422) affected the degree of polymerization and the amount of colanic acid produced (Obadia et al. 2007). In addition to the influence of ExoP on the synthesis of EPS I, the degree of polymerization of this polysaccharide is also affected by environmental conditions such as osmolarity (Breedveld et al. 1990; Becker and Pühler 1998).

In this work, we examined whether ExoP paralogs play a role in polymerization or export of EPS I in S. meliloti. Ionic and osmotic effects on production of this exopolysaccharide were also analyzed. Furthermore, we determined the localization of the ExoP protein in $S$. meliloti cells as well as the influence of the N-terminal ExoP domain on both the phosphorylation state of the C-terminal ExoP domain and EPS I production.

\section{RESULTS}

\section{S. meliloti 2011 contains three paralogs of ExoP displaying structural similarities.}

We started our studies based on the observation that exoP mutants lacking the C-terminal domain still produced HMW EPS I under high osmotic conditions (Becker and Pühler 1998). Hence, we performed a genome analysis searching for putative exoP paralogs encoding proteins that may account for HMW EPS I production in the absence of the C-terminal ExoP domain in S. meliloti. Protein alignments performed using the BLASTP algorithm retrieved the SMc01795, SMb21506, and ExoP2 (SMb21070) proteins as putative candidates with identities to ExoP of $26 \%\left(E\right.$ value $\left.=3.0 \mathrm{e}^{-42}\right), 25 \%(E$ value $=3.0$ $\left.\mathrm{e}^{-36}\right)$, and $29 \%\left(E\right.$ value $\left.=3.0 \mathrm{e}^{-33}\right)$, respectively. Clustal $\mathrm{W}$ alignment of these protein sequences with experimentally confirmed PTK from different bacteria identified a conserved PCP motif located in the N-terminal domain of SMb21506 and ExoP2 (Fig. 1A). The putative ATP binding motifs-Walker A and Walker B-present in the C-terminal domain of these PTK were also detected in the ExoP2 amino acid sequence (Fig. 1B). Although SMc01795 displayed the most significant amino acid alignment, neither Walker A nor Walker B motifs were detected in the C-terminal SMc01795 amino acid sequence (Fig. 1B). Moreover, the C-terminal domain of SMc01795 does not contain any tyrosine residue (Fig. 1C). Because of these results, SMc01795 was excluded from this study.

Protein localization and presence of transmembrane regions were predicted, applying the program TopPredII to the ExoP2 and SMb21506 amino acid sequences. Two transmembrane regions were predicted for the ExoP2 protein. Similar to ExoP, the most probable localization of ExoP2 is the inner membrane and it can also be divided into an N-terminal periplasmic and a C-terminal cytoplasmic domain. Except for these observations, we do not have experimental evidence for these assumptions. Two transmembrane regions and localization in the periplasm were predicted for the SMb21506 protein. In contrast to ExoP, this protein does not contain the C-terminal kinase domain. As in ExoP, coiled-coil motifs were detected in the amino acid sequences of SMb21506 and ExoP2.

ExoP2 does not influence polymerization or export of EPS I.

In order to study the role of the ExoP2 protein in EPS I polymerization or export, we constructed $S$. meliloti exoP2 mutant $\mathrm{Rm} \Delta$ exoP2 carrying a gentamicin resistance cassette replacing $1,837 \mathrm{bp}$ of the exoP2 coding region. In the double mutant $\mathrm{Rm} \Delta$ exoP2/exoP*, this deletion was combined with the exo $P^{*}$ gene solely encoding the $\mathrm{N}$-terminal domain of ExoP. In these mutants, the molecular weight distribution of EPS I produced under low- and high-salinity conditions $(0$ and $240 \mathrm{mM}$ $\mathrm{NaCl}$, respectively) was examined by gel permeation chromatography. The molecular weight distribution of EPS I produced by mutant $\mathrm{Rm} \Delta$ exoP 2 and the Rm2011 wild-type strain did not differ under high- or low-salinity conditions. In both strains, HMW and LMW EPS I was detected at a ratio of 60:40 under low-salinity and 80:20 under high-salinity conditions (Fig. 2A and $\mathrm{B}$ ).

In the RmexoP* mutant, only LMW EPS I was produced under low-salinity conditions; however, both HMW and LMW EPS I were detected under hypersaline conditions at a ratio of 70:30 (Fig. 2A and B). A mutation in exoP2 did not result in appreciable modifications of the ratio of HMW to LMW EPS I both in the wild type and in the background of the exoP* mutation (Fig. 2A and B).

Because no alteration in the ratio of HMW to LMW EPS I or in the amount of EPS I produced (Table 1) was observed in the exoP2 mutant, we examined the lipopolysaccharide (LPS) profiles of the single exoP2 and double exoP2/exoP* mutants. The LPS profiles of the wild-type strain as well as the $\mathrm{Rm} \Delta$ exoP2 and $\mathrm{Rm} \Delta$ exoP2/exoP* mutants showed no appreciable differences when analyzed by sodium dodecyl sulfate polyacrylamide gel electrophoresis (SDS-PAGE), indicating that ExoP2 is not involved in LPS biosynthesis (data not shown).

Taking into account that ExoP2 seems not to influence EPS I or LPS biosynthesis, we determined whether ExoP2 is expressed under the conditions assayed for EPS I production as well as during symbiosis with $M$. sativa. Hence, the relative expression of exoP2 under hypersaline (glutamate-D-mannitolsalts [GMS], $240 \mathrm{mM} \mathrm{NaCl}$ ) and hyperosmotic conditions (GMS, $375 \mathrm{mM}$ sucrose) in comparison with the control (GMS) was determined by quantitative real-time polymerase chain reaction (qPCR) in the Rm2011 wild type. Under highsalinity conditions, no differences were observed in the relative abundance of exoP2 transcripts (fold change $0.83 \pm 0.21$ ) compared with low-salinity conditions. In contrast, a sevenfold increase in expression of exoP2 was observed under hyperosmotic conditions $(7.28 \pm 3.71)$ with regard to the low osmotic conditions.

The Rm $\Delta$ exoP2 mutant induced efficient nodules on $M$. sativa (Table 2). In addition to the symbiotic phenotype, the expression of exoP2 during symbiosis was evaluated in $M$. sativa plants inoculated with exoP2 mutant strain 2011mTn5STM.4.05.C08 carrying an mTn5-STM transposon insertion generating a transcriptional fusion of a gusA reporter gene to exoP2. The expression of exoP2 was found to be higher in nodule primordia ( 7 days after inoculation) than in mature nodules (21 days after inoculation), suggesting that ExoP2 might play a role during symbiosis with $M$. sativa (data not shown).

\section{In the absence of the ExoP C-terminal domain, the auxiliary protein $\mathrm{SMb21506}$ is required for polymerization or export of EPS I.}

To analyze whether protein SMb21506 affects the production of HMW EPS I, we generated the polar mutant Rm19 by sitedirected integration of plasmid p19Y21506 into the SMb21506 coding region. Because the putative polysaccharide polymerase gene $\mathrm{SMb} 21505$ is located directly downstream of the $\mathrm{SMb} 21506$ gene and might have been affected by this mutation, $\mathrm{SMb} 21506$ mutant $\mathrm{Rm} 18$ was additionally constructed. In this mutant, the lac promoter of the integrated plasmid p18Y21506 directs transcription of the $\mathrm{SMb} 21505$ gene. Integration of these plasmids into the genome of $\operatorname{exo} P^{*}$ mutant $\operatorname{Rm} \Delta \mathrm{P} * 1$ resulted in 
the double mutants $\mathrm{Rm} 18 / \Delta \mathrm{P} * 1$ and $\mathrm{Rm} 19 / \Delta \mathrm{P} * 1$. The molecular weight distribution of EPS I produced by mutants Rm18, $\mathrm{Rm} 19, \mathrm{Rm} 18 / \Delta \mathrm{P}^{*} 1$, and $\mathrm{Rm} 19 / \Delta \mathrm{P}^{*} 1$ under hypersaline and low-salinity conditions was analyzed by gel permeation chromatography. EPS I was obtained from supernatants of cultures grown for 10 days in GMS medium supplemented with either 0 or $240 \mathrm{mM} \mathrm{NaCl}$. Both single mutants, Rm18 and Rm19, grown in GMS medium without $\mathrm{NaCl}$ produced less HMW EPS I than wild-type Rm2011 under the same conditions (Fig. 3A). This difference in the EPS I profiles of both mutants affected in
SMb21506 and the Rm2011 wild-type strain was not observed when these strains were grown in GMS medium supplemented with $240 \mathrm{mM} \mathrm{NaCl}$ (Fig. 3B).

In mutant $\mathrm{Rm} \Delta \mathrm{P}^{*} 1$, only LMW EPS I was detected in supernatants from GMS medium; however, in GMS medium supplemented with $240 \mathrm{mM} \mathrm{NaCl}$, both HMW EPS I and LMW EPS I were detected (Fig. 3A and B). Interestingly, the double mutant $\mathrm{Rm} 18 / \Delta \mathrm{P} * 1$ was unable to produce HMW EPS I under both conditions tested ( 0 and $240 \mathrm{mM} \mathrm{NaCl}$ ) (Fig. 3A and B).

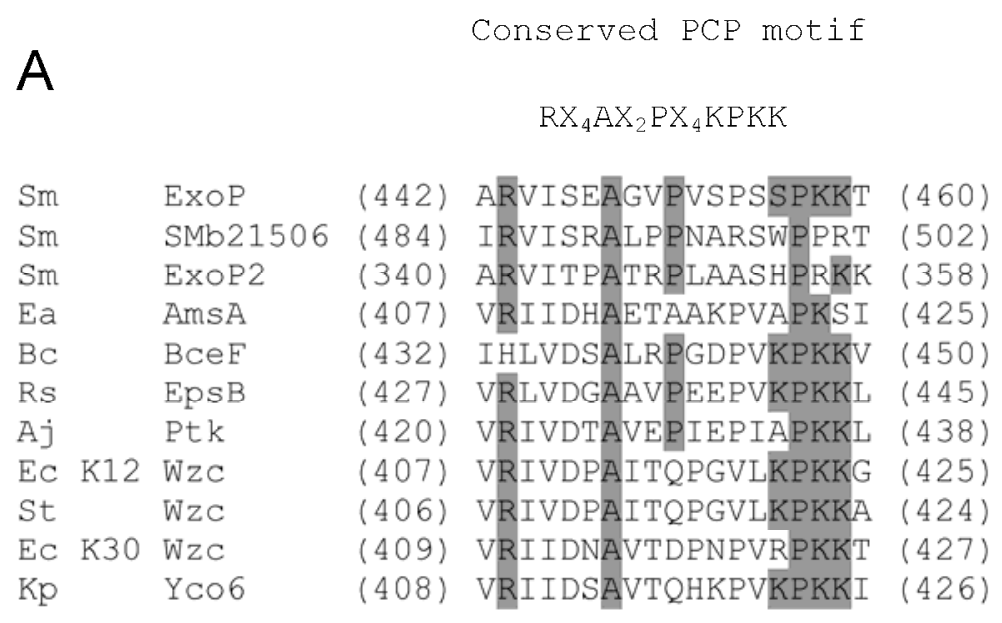

B

\begin{tabular}{|c|c|c|c|c|c|}
\hline & & & $A / G] X X X X$ & & \\
\hline Sm & ExoP & $(579)$ & AIASALPDEGKSIIA & (593 & \\
\hline $\mathrm{Sm}$ & $\mathrm{SMC01795}$ & $(536)$ & VSVSPGGDEG-STAT & (549 & - \\
\hline m & ExoP2 & $(451)$ & GVTSĀTPDDGKSTVA & (465 & )-- \\
\hline a & AmsA & 3) & MITGASPGIGKTFVC & (547 & \\
\hline C K12 & WzC & 30) & MMTGVSPSIGKTFVC & (544 & \\
\hline t & WzC & 29) & MLTGVSPSIGKTFVC & (543 & ) - \\
\hline c K30 & WzC & 0) & MISGASPSAGKTEIS & (544 & )- \\
\hline p & $Y \cos 6$ & 531) & MISGÄSPNAGKTFVS & (545 & -1 \\
\hline 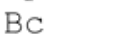 & & & VLTGPTPGIGKSFLT & (567 & )- \\
\hline 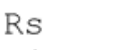 & $E$ & & VLTGPTPG & (561 & )-- \\
\hline & Pt & & TISGPAPE & 53 & $1--$ \\
\hline & & & $-2=0$ & & \\
\hline & & 758) & $\mathrm{YSD}$ & $1+0$ & (1/7) \\
\hline & $\mathrm{SMC}$ & $704)$ & $-\mathrm{PDFPI}$ & -- & $(71)$ \\
\hline & Exol & $(618)$ & -LSTRQYRK & -- & 1632 \\
\hline a & AmsA & $(704)$ & -KSANNYGYGYDYYDYS & SYQQ & $(72)$ \\
\hline c K12 & WzC & ) & -RASAYQDYGYYEYEYK & $\mathrm{KSD}$ & $(718)(8))(x)$ \\
\hline 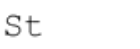 & WzC & $(7$ & -RATGYQDYGYYEYEYQ & QSD & (71 \\
\hline $\mathrm{K} 30$ & $\mathrm{WzC}$ & & -KASSYYRY & SYY & (71 \\
\hline & $\mathrm{YCO}$ & 2) & KYGYGYNYYDYS & SYS & 171 \\
\hline 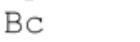 & $\mathrm{Bce}$ & 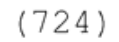 & -KARGYGRYAAVHEYL & LSA & $(74$ \\
\hline & EpsB & $(72$ & GYGSRYGRYRYVQYGYT & TSN & $(74$ \\
\hline . & Ptk & $(710)$ & -SSAGYGYGYGYMAYA & $\mathrm{AYY} K$ & $(727$ \\
\hline
\end{tabular}

Fig. 1. Amino acid alignments between experimentally confirmed bacterial protein tyrosine kinases (PTK) and Sinorhizobium meliloti ExoP paralogs. A, Conserved polysaccharide co-polymerase motif present in the N-terminal domain of PTK (highlighted in gray); B, Walker-A and Walker-B ATP-binding motifs found in PTK (highlighted in gray); C, C-terminal tyrosine cluster of PTK is shown highlighted in gray. X indicates any amino acid, h indicates a hydrophobic amino acid, and alternative residues are enclosed in brackets. $\mathrm{Sm}=$ S. meliloti ExoP, SMb21506, SMc01795, and ExoP2; Ea = Erwinia amylovora $\mathrm{AmsA} ; \mathrm{Bc}=$ Burkholderia cepacia $\mathrm{BceF} ; \mathrm{Rs}=$ Ralstonia solanacearum $\mathrm{EpsB} ; \mathrm{Aj}=$ Acinetobacter johnsonii $\mathrm{Ptk} ; \mathrm{Ec} \mathrm{K} 12=$ Escherichia coli $\mathrm{K} 12$ Wzc; Ec K30 = E. coli $\mathrm{K} 30 \mathrm{Wzc} ; \mathrm{St}=$ Salmonella enterica serovar typhimurium Wzc; and Kp = Klebsiella pneumoniae Yco6. 
Compared with the wild type, SMb21506 mutant Rm18 produced similar amounts of EPS I under both hypersaline and hyperosmotic conditions (Table 1 ). Single mutant $\mathrm{Rm} \Delta \mathrm{P}^{*} 1$, as reported previously (Becker and Pühler 1998), produced only $10 \%$ of the amount of EPS I produced by the wild type, but this amount was increased to $40 \%$ when the medium was supplemented with $240 \mathrm{mM} \mathrm{NaCl}$. Such an increment was not observed in double mutant SMb21506/ $\mathrm{P} * 1$ (Table 1). To confirm that hexose equivalents measured in the supernatant of these mutants were derived from EPS I, S. meliloti exoY mutant RmAR9007, deficient in production of EPS I (Keller et al. 1995), was included as a control. Culture supernatants of this exoY mutant contained only a low amount of hexose, probably derived from cyclic glucans (Keller et al. 1995), under all conditions tested (GMS, GMS + $240 \mathrm{mM} \mathrm{NaCl}$, or GMS + 375 $\mathrm{mM}$ sucrose) (Table 1).

No differences were observed in the molecular weight distribution of EPS I from the culture supernatants of mutants
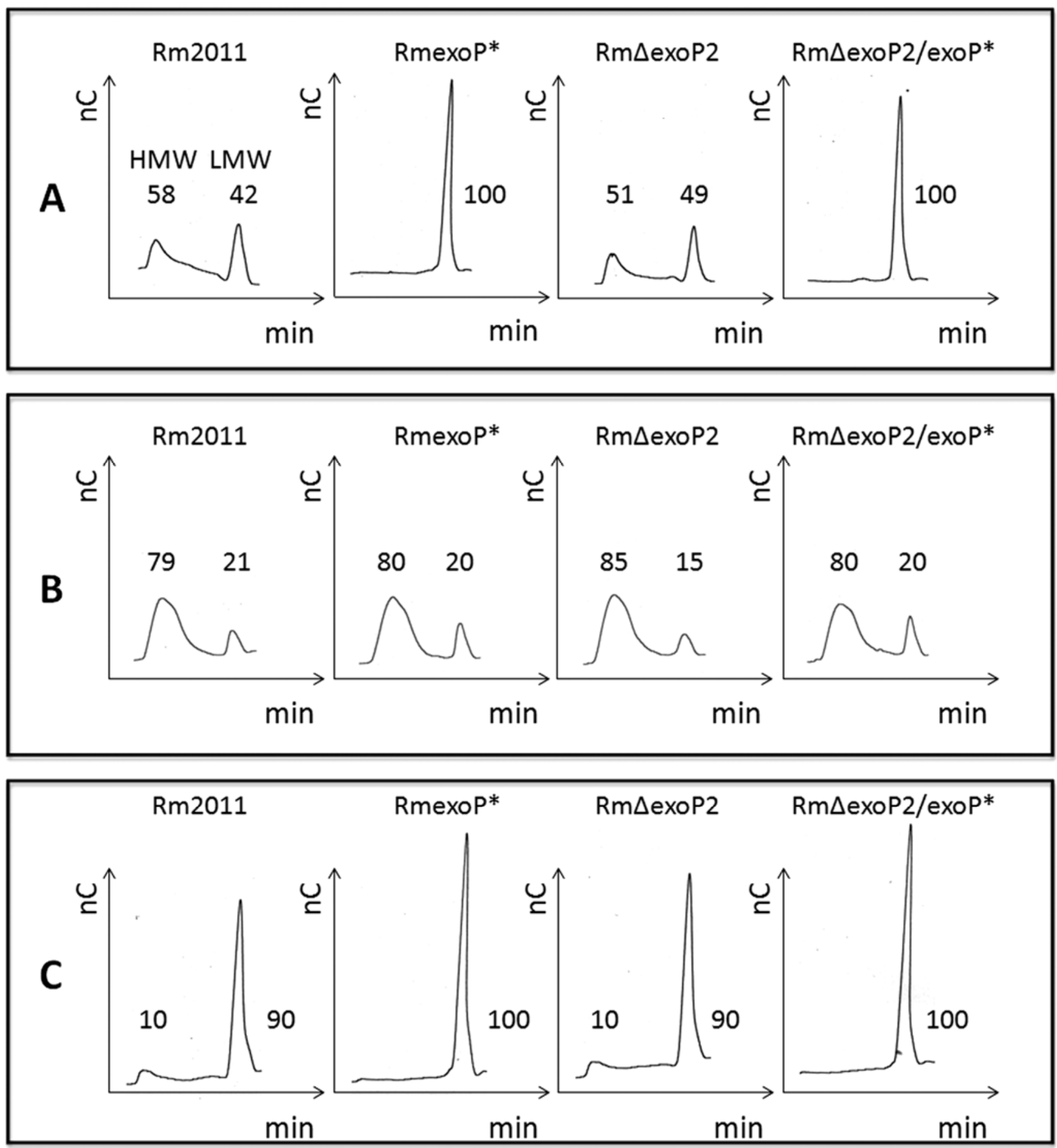

Fig. 2. Molecular-weight distribution of exopolysaccharide succinoglycan (EPS I) produced by Sinorhizobium meliloti ExoP2 and ExoP mutants under hypersaline and hyperosmotic conditions. Succinoglycan fractions were obtained from culture supernatants of A, glutamate-D-mannitol-salts (GMS) medium, 0.09 osmol/liter; B, GMS medium supplemented with $240 \mathrm{mM} \mathrm{NaCl}, 0.5$ osmol/liter; or C, GMS medium supplemented with $375 \mathrm{mM}$ sucrose, 0.5 osmol/liter. HMW and LMW indicate high molecular weight EPS I and low molecular weight EPS I, respectively. Numbers indicate the ratio of HMW to LMW EPS I deduced from the corresponding peak areas. Succinoglycan fractions were subjected to high-performance liquid chromatography gel permeation chromatography. In all cases, EPS samples corresponding to $100-\mu \mathrm{g}$ glucose equivalents were loaded. 
$\mathrm{Rm} 18 / \Delta \mathrm{P} * 1$ and $\mathrm{Rm} 19 / \Delta \mathrm{P} * 1$, indicating that the observed phenotype was not a consequence of a polar effect of the plasmid integration in SMb21506 on transcription of SMb21505. These results suggest that production of HMW EPS I is influenced by the SMb21506 protein. Such an effect is more evident in the absence of the C-terminal ExoP domain. In agreement with the ability to produce both HWM and LMW EPS I, SMb21506 mutant Rm18 induced pink nodules on $M$. sativa (Table 2).

Transcript levels of SMb21506 were compared under ionic and osmotic conditions by qPCR. Under hypersaline conditions (GMS $+240 \mathrm{mM} \mathrm{NaCl}$ ), no differences were observed in the relative abundance of $\mathrm{SMb} 21506$ transcripts (fold change $0.82 \pm 0.34)$ compared with low-salinity (GMS $+0 \mathrm{mM} \mathrm{NaCl})$ conditions. However, under hyperosmotic conditions (GMS + $375 \mathrm{mM}$ sucrose) compared with GMS medium not supplemented with sucrose, a twofold increase in expression of SMb21506 was observed $(2.82 \pm 0.44)$. Despite the higher expression of SMb21506 under hyperosmotic conditions, no significant changes were observed in the molecular weight distribution of EPS I produced by the wild-type strain and SMb21506 mutant Rm18 under this condition (Fig. 3C).

\section{Polymerization of EPS I is affected by the ionic strength of the medium rather than the osmolarity.}

Because an enhanced production HMW EPS I was observed at high osmolarity (Becker and Pühler 1998), we examined whether both ionic and osmotic conditions can cause this effect. Culture supernatants containing EPS I from GMS medium and GMS medium supplemented with $240 \mathrm{mM} \mathrm{NaCl}$ ( 0.5 osmol/liter) or $375 \mathrm{mM}$ sucrose $(0.5$ osmol/liter $)$ were subjected to gel permeation chromatography. Wild-type strain Rm2011 produced HMW and LMW EPS I at a ratio of 58:42 (Fig. 2A) when cultured in GMS medium (0.09 osmol/liter) and displayed an enhanced production of HMW EPS I at the expense of LMW EPS I (79:21) in GMS medium containing $240 \mathrm{mM} \mathrm{NaCl}$ (Fig. 2B), as previously reported (Becker and Pühler 1998). However, such an increase in HMW EPS I production was not observed in GMS medium supplemented with sucrose at a comparable osmolarity. In contrast, a ratio of HMW to LMW EPS I of 10:90 was found under this condition (Fig. 2C). Similar results were obtained for mutant RmexoP*, which produced HMW and LMW EPS I at the ratios of 0:100, 80:20, and 0:100 in medium supplemented with $0 \mathrm{mM} \mathrm{NaCl}$, $240 \mathrm{mM} \mathrm{NaCl}$, and $375 \mathrm{mM}$ sucrose, respectively (Fig. 2A through $\mathrm{C}$ ). These results suggest that ionic rather than osmotic effects influence production of HMW EPS I in S. meliloti 2011. It is important to note that neither hypersaline nor hyperosmotic conditions altered the amount of EPS I produced by wild-type strain Rm2011 (Table 1).

\section{The ExoP protein localizes}

\section{at the inner membrane of $S$. meliloti cells.}

The localization and phosphorylation state of ExoP in $S$. meliloti was determined by cell fractionation. Proteins from cytosol or periplasm, inner membrane, and outer membrane fractions were obtained from cultures grown in tryptone yeast (TY) medium to an optical density at $600 \mathrm{~nm}\left(\mathrm{OD}_{600}\right)$ of 0.8 , separated by SDS-PAGE, and assayed by Western immunoblotting with either the anti-ExoP antibody or the anti-phosphotyrosine antibody.

When probed with the anti-ExoP antibody, an approximately $80-\mathrm{kDa}$ band consistent with the expected size of ExoP (84 $\mathrm{kDa})$ was detected in the inner membrane fraction, suggesting that ExoP is localized at the inner membrane of $S$. meliloti cells (Fig. 4A). As expected, this band was absent in the Rm $\Delta$ exoP mutant and also was not detected in cytosol-periplasm, periplasm, and outer membrane fractions (data not shown). Localization of ExoP at the inner membrane is in accordance with previous results obtained using translational exoP-lacZ

Table 1. Production of succinoglycan by Sinorhizobium meliloti wild type and mutants under hypersaline and hyperosmotic conditions

\begin{tabular}{|c|c|c|c|c|}
\hline \multirow[b]{2}{*}{ Strain } & \multirow[b]{2}{*}{ Mutation } & \multicolumn{3}{|c|}{ Glucose equivalents (mg/liter) $^{a}$} \\
\hline & & GMS & GMS + NaCl & GMS + sucrose \\
\hline Rm2011 & None (wild type) & $798 \pm 23$ & $763 \pm 31$ & $753 \pm 33$ \\
\hline $\mathrm{Rm} \Delta \mathrm{P}^{*} 1$ & exoP* & $83 \pm 16$ & $320 \pm 6$ & $85 \pm 12$ \\
\hline RmexoP* & exoP* & $92 \pm 12$ & $260 \pm 20$ & $90 \pm 13$ \\
\hline $\mathrm{Rm} \Delta \mathrm{exoP} 2$ & exoP2 & $826 \pm 37$ & $770 \pm 41$ & $763 \pm 36$ \\
\hline $\mathrm{Rm} \Delta$ exoP2/exoP* & exoP2/exoP* & $264 \pm 28$ & $288 \pm 15$ & $245 \pm 12$ \\
\hline $\mathrm{Rm} \Delta \mathrm{exoP} / \mathrm{pExoP}$ & None (wild type) & $857 \pm 42$ & $833 \pm 25$ & $791 \pm 32$ \\
\hline $\mathrm{Rm} 18$ & $\mathrm{SMb} 21506$ & $777 \pm 42$ & $766 \pm 32$ & $746 \pm 24$ \\
\hline $\mathrm{Rm} 18 / \Delta \mathrm{P} * 1$ & $\mathrm{SMb} 21506 /$ exo $^{*}$ & $90 \pm 7$ & $88 \pm 6$ & $79 \pm 13$ \\
\hline RmAR9007 & $\operatorname{exo} Y$ & $29 \pm 1$ & $28 \pm 2$ & $25 \pm 1$ \\
\hline
\end{tabular}

${ }^{a}$ Average of three biological replicates with two technical replicates each \pm standard deviation. GMS = glutamate-D-mannitol-salts (0.09 osmol/liter), GMS $+\mathrm{NaCl}=\mathrm{GMS}$ plus $240 \mathrm{mM} \mathrm{NaCl}(0.5$ osmol/liter $)$, and GMS + sucrose $=$ GMS plus $375 \mathrm{mM}$ sucrose $(0.5$ osmol/liter $)$.

Table 2. Symbiotic and calcofluor phenotypes of the different Sinorhizobium meliloti Rm2011 mutants ${ }^{\mathrm{a}}$

\begin{tabular}{|c|c|c|c|c|}
\hline Strain & Mutation & No. of pink nodules/plant & No. of white nodules/plant & Calcofluor phenotype ${ }^{b}$ \\
\hline $\mathrm{Rm} 2011$ & None (wild-type) & $7.7 \pm 2.0$ & 0 & + \\
\hline $\mathrm{Rm} \Delta \mathrm{exoP}$ & $\operatorname{exoP}$ & 0 & $6.5 \pm 1.4$ & - \\
\hline $\mathrm{Rm} \Delta$ exoP/pExoP & None (wild-type) & $6.4 \pm 1.6$ & 0 & + \\
\hline $\mathrm{Rm} \Delta \mathrm{P} * 1$ & exoP* & 0 & $8.0 \pm 1.8$ & nd \\
\hline $\mathrm{Rm} \Delta \mathrm{exoP} 2$ & exoP2 & $7.3 \pm 1.7$ & 0 & + \\
\hline RmR443L & exoP, R443L & $7.4 \pm 1.8$ & 0 & nd \\
\hline $\mathrm{RmP} 457 \mathrm{~S}$ & exoP, $\mathrm{P} 457 \mathrm{~S}$ & $1.8 \pm 0.4$ & $4.5 \pm 1.1$ & nd \\
\hline RmK459I & exoP, K459I & $6.5 \pm 1.5$ & 0 & nd \\
\hline $\mathrm{Rm} 18$ & SMb21506 & $6.8 \pm 1.4$ & 0 & + \\
\hline $\mathrm{Rm} \Delta \mathrm{exoPn}$ & exoPn & 0 & $7.3 \pm 1.6$ & - \\
\hline RmAR9007 & $\operatorname{exo} Y$ & 0 & $7.1 \pm 1.2$ & - \\
\hline
\end{tabular}

${ }^{a}$ Results represent the average from three independent experiments \pm standard deviation.

b Symbols: + and - = bright and dark, respectively, under UV illumination; nd = not determined. 
fusions (Becker et al. 1995). Immunoblots probed with the antiphosphotyrosine antibody did not show any detectable signal, indicating that the ExoP protein did not contain phosphorylated tyrosine residues under the conditions tested (Fig. 4A).

Taking into account the effect of salinity on the production of HMW EPS I, we examined whether saline conditions also affect the amount of ExoP protein. Strains were grown to an $\mathrm{OD}_{600}$ of 0.8 in TY medium and TY medium supplemented with $240 \mathrm{mM} \mathrm{NaCl}$. Inner membrane fractions were subjected to Western immunoblotting and probed with either the peptide antibody anti-ExoP or the anti-phosphotyrosine antibody. A decreased amount of ExoP was detected in membrane fractions from wild-type strain Rm2011 grown at high salinity compared with low-salinity conditions (Fig. 4B), and the same results were observed in the complemented strain $\mathrm{Rm} \Delta$ exoPpExoP (Fig. 4B). In contrast, immunoblots probed with the anti-phosphotyrosine antibody revealed a weak signal corresponding to the tyrosine-phosphorylated ExoP protein under low-salinity conditions only (Fig. 4B). The finding that phosphorylation of the ExoP protein was not detected at high salinity seemed to be related more to the amount of ExoP protein than to an effect of $\mathrm{NaCl}$ on ExoP phosphorylation. In order to test whether this assumption was correct, we performed a Western immunoblotting assay using inner membrane fractions obtained from cultures grown for 10 days in GMS medium supplemented with $240 \mathrm{mM} \mathrm{NaCl}$ (the same growth conditions employed for EPS I analysis). Under these conditions, tyrosine residues of the ExoP protein appeared phosphorylated (Fig. $4 \mathrm{C})$, indicating that saline conditions did not alter the state or degree of ExoP phosphorylation.

\section{Specific amino-acid substitutions \\ in the conserved PCP motif result \\ in an increased phosphorylation state of ExoP.}

Previously, it was shown that specific amino acid substitutions in the conserved PCP motif of the N-terminal ExoP domain affected the molecular-weight distribution of EPS I (Becker and Pühler 1998). The amino acid substitutions R443L and P457S both resulted in enhanced production of LMW EPS I at the expense of the HMW fraction but did not affect the amount of EPS I produced (Becker and Pühler1998). Taking into account these results, we examined the phosphory-

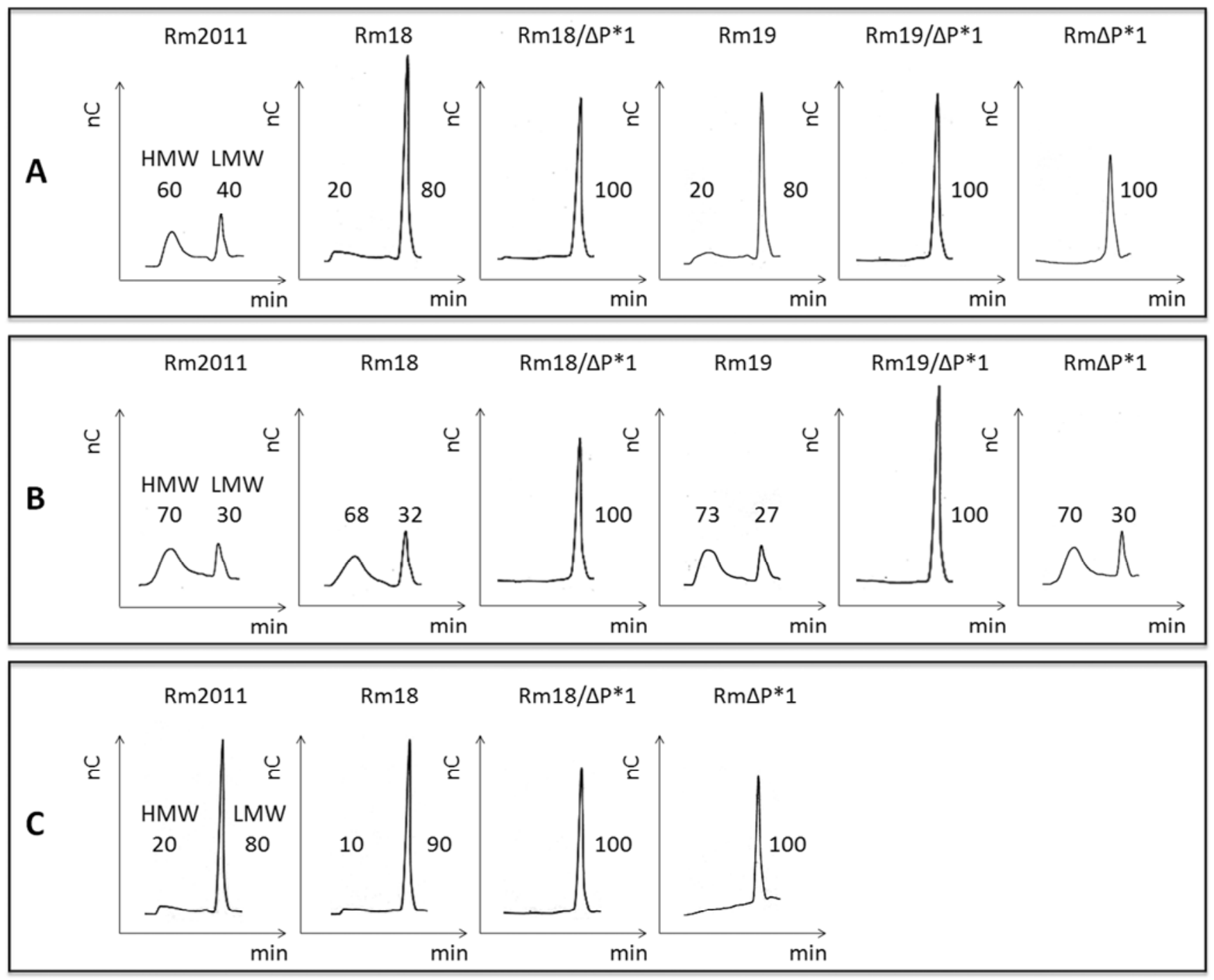

Fig. 3. Molecular-weight distribution of exopolysaccharide succinoglycan (EPS I) produced by SMb21506 and ExoP mutants under hypersaline and hyperosmotic conditions. EPS I fractions were obtained from culture supernatants of A, glutamate-D-mannitol-salts (GMS) medium, 0.09 osmol/liter; B, GMS medium supplemented with $240 \mathrm{mM} \mathrm{NaCl}, 0.5$ osmol/liter; or C, GMS medium supplemented with $375 \mathrm{mM}$ sucrose, 0.5 osmol/liter. HMW and LMW indicate high molecular weight EPS I and low molecular weight EPS I, respectively. Numbers indicate the ratio of HMW to LMW EPS I deduced from the corresponding peak areas. EPS I fractions were subjected to high-performance liquid chromatography gel permeation chromatography. In all cases, EPS samples corresponding to $100-\mu \mathrm{g}$ glucose equivalents were loaded. 

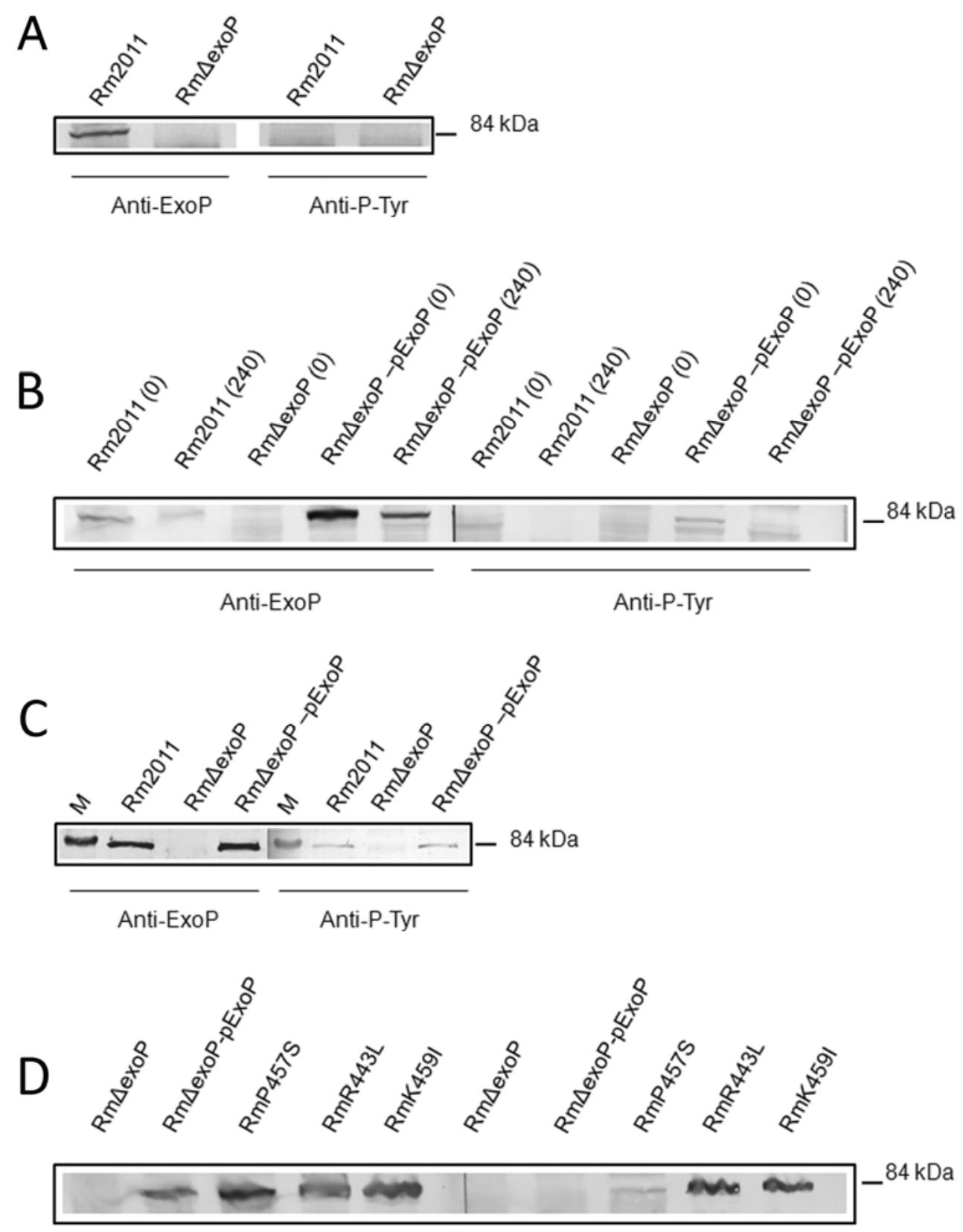

Anti-ExoP

Anti-P-Tyr

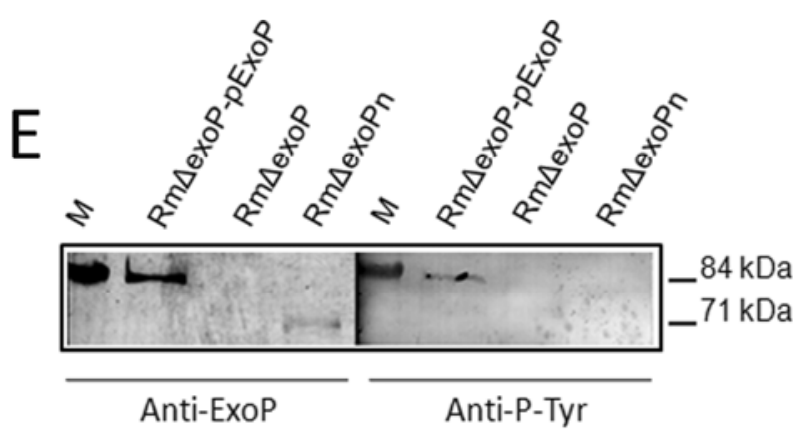

Fig. 4. Immuno Western blot analysis of inner membrane proteins from the Sinorhizobium meliloti wild type and mutants probed with the anti-ExoP antibody (Anti-ExoP) or the anti-phosphotyrosine antibody (Anti-P-Tyr). A, Immunodetection of ExoP in inner membrane fractions of S. meliloti. Strains were cultured in tryptone yeast (TY) medium. B, Effect of hypersaline conditions on the amount or stability of ExoP. Strains were cultured in TY medium ( 0 mM $\mathrm{NaCl}$ ) or in TY medium supplemented with $240 \mathrm{mM} \mathrm{NaCl}$ (240). C, Phosphorylation state of ExoP in $S$. meliloti cultured for 10 days in glutamate-Dmannitol-salts medium supplemented with $240 \mathrm{mM} \mathrm{NaCl}$. D, Effect of amino acid substitutions within the polysaccharide co-polymerase motif of the Nterminal ExoP domain on the tyrosine-phosphorylation state of the C-terminal ExoP domain. E, Immunodetection and phosphorylation state of the truncated ExoP protein present in mutant strain $\mathrm{Rm} \Delta$ exoPn. 
lation state of the ExoP protein in these mutants and in mutant RmK459I by Western immunoblotting.

Inner membrane fractions were obtained from cultures grown in $\mathrm{TY}$ medium to an $\mathrm{OD}_{600}$ of 0.8. Immunoblots probed with the anti-ExoP antibody exhibited a signal corresponding to the ExoP protein in mutants RmR443L, RmP457S, and RmK459I as well as in the complemented strain Rm $\Delta$ exoP-pExoP (Fig. 4D). Immunoblots using the anti-phosphotyrosine antibody revealed a higher degree of tyrosine phosphorylation of the altered ExoP protein of mutants RmR443L and RmK459I compared with the wild-type ExoP protein in the complemented strain. Mutant RmP457S also showed an increased phosphorylation of ExoP compared with the wild-type ExoP protein but this increment was less significant than that observed for mutants RmR443L and RmK459I (Fig. 4D). These results imply that tyrosine phosphorylation within the C-terminal ExoP domain could be modulated by conformational changes within the $\mathrm{N}$-terminal domain.

Because EPS I plays an important role in nodule invasion, we tested whether or not the altered production of EPS I affects the ability of mutants RmR443L and RmP457S to establish an effective symbiosis with $M$. sativa. Both strains almost exclusively produced LMW EPS I under normal culture conditions (Becker and Pühler 1998). Interestingly, RmR443L induced effective pink elongated nodules, whereas mutant RmP457S induced both ineffective white and effective pink nodules at a ratio of 70:30. In contrast to the white noninfected pseudonodules induced by the $S$. meliloti exoY mutant RmAR9007, ineffective nodules induced by mutant RmP457S were white, elongated, fix-minus nodules. Mutant RmK459I, which produced HMW and LMW EPS I at a ratio comparable with the wild-type strain Rm2011 (Becker and Pühler 1998), induced effective nodules on $M$. sativa (Table 2). Bacteria reisolated from pink and white nodules carried the plasmid causing the mutation and displayed the same phenotypes as the mutant strains used for inoculation of the host plant. This indicates that these mutations were stable and that suppressor mutations did not occur.

\section{The N-terminal domain of ExoP is essential for EPS I production or export.}

The presence of four putative coiled-coil motifs within the $\mathrm{N}$-terminal domain of ExoP was predicted using the algorithm COILS (Lupas et al. 1991). Such motifs are found in proteins able to modulate their activity by protein-protein interactions. Mutant $\mathrm{Rm} \Delta$ exoPn was constructed in order to evaluate whether the N-terminal domain of ExoP influences phosphorylation of tyrosine residues in the $\mathrm{C}$-terminal ExoP domain as well as polymerization or export of EPS I. This mutant is characterized by deletion of a 411-bp fragment encoding one of the four predicted coiled-coil motifs. Strains were grown in GMS medium for 10 days and inner membrane fractions were analyzed by Western immunoblotting with the anti-ExoP antibody. A band of approximately $71 \mathrm{kDa}$ corresponding to the truncated ExoP protein was detected in the inner membrane fraction of $S$. meliloti $\mathrm{Rm} \Delta$ exoPn, indicating that localization and antigenic properties of the truncated protein were not changed (Fig. 4E). Moreover, topology predictions applying the program TopPredII indicated that localization of the second transmembrane region also was unaltered (data not shown). Immunoblots probed with the anti-phosphotyrosine antibody revealed that, in contrast to the wild-type ExoP protein, tyrosine residues of the truncated ExoPn protein were not phosphorylated (Fig. 4 E).

The phenotype of mutant $\mathrm{Rm} \Delta$ exoPn grown on GMS agar medium containing calcofluor indicated that this strain did not produce EPS I (Table 2). In accordance with this phenotype, the formation of pseudonodules in the nodulation assay confirmed that mutant $\mathrm{Rm} \Delta \mathrm{exoPn}$ is unable to invade $M$. sativa nodules (Table 2).

\section{DISCUSSION}

Mutations in the $S$. meliloti exoP gene blocked polymerization of EPS I, suggesting that the ExoP protein is required for this process (Becker et al. 1995; Gonzalez et al. 1998). A mutation within the C-terminal ExoP domain did not completely abolish EPS I polymerization but resulted in a decreased production of EPS I with an increased ratio of the LMW to the HMW forms. This suggested that this protein domain is not essential for production and export of EPS I but may, instead, possess a regulatory function (Becker et al. 1995). The presence of the ExoP paralogs ExoP2 and SMb21506 in S. meliloti 2011 raises the question of whether these proteins participate in EPS I polymerization and whether they are required for the production of HMW EPS I observed in mutants lacking the Cterminal ExoP domain.

The observation that the exoP2/exoP* double mutant produced HMW EPS I to the same extent as the single exo $P^{*}$ mutant when grown in high-salinity conditions argues against a role of ExoP2 in EPS I biosynthesis. This result is not surprising because E. coli possesses three ExoP orthologs, $\mathrm{Wzc}_{\mathrm{cps}}$, $\mathrm{Wzc}_{\mathrm{ca}}$, and Etk, which function in distinct pathways (Ilan et al. 1999; Vincent et al. 2000; Wugeditsch et al. 2001). Identical LPS profiles of the exoP 2 mutant and the wild type also make it unlikely that ExoP2 plays an important role in LPS synthesis. ExoP2 was expressed during nodule development and showed upregulation under hyperosmotic conditions, suggesting that it may be involved in the synthesis of an as-yet-unidentified polysaccharide.

The SMb21506 protein displays similarities to the N-terminal periplasmic domain of ExoP but lacks the C-terminal kinase domain. A SMb21506 mutant produced much less HMW EPS I than the wild type and, in the background of a SMb21506 mutation, the $\operatorname{exo}^{*}$ mutant was no longer able to produce HMW EPS I under hypersaline conditions. Therefore, we speculate that the SMb21506 protein was responsible for the production of HMW EPS I observed in exoP* mutants lacking the C-terminal ExoP domain. The mechanism by which SMb21506 influences EPS I polymerization remains to be determined. However, $\mathrm{SMb} 21506$ does not contain a C-terminal domain and the protein was predicted to be located in the periplasmic space. Therefore, it is unlikely that the $\mathrm{SMb} 21506$ protein substitutes for the function of the C-terminal kinase domain of ExoP. It is tempting to speculate that this protein influences polymerization or export of EPS I through interactions with the N-terminal periplasmic ExoP domain. Indeed, the presence of coiled-coil motifs was predicted for SMb21506.

It is well documented that environmental conditions such as salinity modify bacterial cell envelopes. Such modifications often involve changes in rhizobial EPS or LPS profiles (Lloret et al. 1995, 1998; Zahran 1999; Soussi et al. 2001). This study showed that specifically high salinity but not high osmolarity results in enhanced production of HMW EPS I. Studies of genome-wide expression profiling in $S$. meliloti demonstrated the induction of exoN, exoY, exoH, and exoK in response to salt stress (Rüberg et al. 2003; Domínguez-Ferreras et al. 2006). ExoK is an endoglycanase that specifically depolymerizes nascent EPS I polymers to LMW oligosaccharides but not EPS I that has accumulated in culture supernatants. The activity of ExoK requires succinylation of EPS I, which is carried out by ExoH (York and Walker 1998). According to these results, a lower ratio of HMW to LMW EPS I might be expected in $S$. meliloti cultures supplemented with $\mathrm{NaCl}$ than in cultures 
without this supplementation. Our results, as well as those obtained by Becker and Pühler (1998), showed the opposite situation: the presence of $\mathrm{NaCl}$ specifically resulted in an increased amount of HMW EPS I.

ExoN and ExoY participate in the biosynthesis of EPS I, with the former functioning as an UDP-glycosyl pyrophosphorylase involved in synthesis of a nucleotide sugar and the latter acting to initiate the biosynthesis itself (Glucksmann et al. 1993; Reuber and Walker 1993). Enhanced levels of ExoN and ExoY may result in an increment in the amount of octasaccharide repeating units under salt stress. In addition to or instead of enhanced polymerization of EPS I, a reduced sensitivity of EPS I polymers to depolymerization by endoglycanases may contribute to enhanced levels of HMW EPS I under high-salinity conditions. Such an enhanced resistance to endoglycanases may be caused by structural changes of the EPS I polymer under this condition. In saline environments, the enhanced production of HMW EPS I could be an advantage for the survival of $S$. meliloti because highly polymerized EPS I probably offers more protection against desiccation than LMW EPS I (Vriezen et al. 2007).

Previously, it was reported that the C-terminal domain of ExoP has ATPase activity and is phosphorylated on tyrosine residues in E. coli (Niemeyer and Becker 2001). Specific amino acid substitutions in the highly conserved Walker A ATP-binding motif resulted in much lower levels of EPS I produced which consisted only of monomers of the octasaccharide repeating unit (Niemeyer and Becker 2001). Moreover, site-directed mutagenesis of specific tyrosine residues in the cytoplasmic domain of ExoP resulted in an altered ratio of HMW to LMW EPS I (Niemeyer and Becker 2001), indicating that tyrosine phosphorylation influences EPS I polymerization.

Tyrosine kinase activities of PTK have been demonstrated to play a central role in the biosynthesis of capsular polysaccharides and exopolysaccharides in several bacteria, including $E$. coli $\mathrm{K} 30$, E. coli K12, Streptococcus pneumoniae, Acinetobacter lwoffii, and Erwinia amylovora (Cozzone et al. 2004). However, contrasting results were reported with respect to the requirement of tyrosine phosphorylation for polysaccharide polymerization and export. For example, in Escherichia coli K30, the phosphorylation of $\mathrm{Wzc}_{\mathrm{cps}}$ was shown to be essential for capsule expression (Wugeditsch et al. 2001) but phosphorylation of $\mathrm{Wzc}_{\mathrm{ca}}$ in $E$. coli $\mathrm{K} 12$ resulted in decreased production of colanic acid (Vincent et al. 2000). In Acinetobacter lwoffii, the production of the emulsan polysaccharide is reduced when Wzc is phosphorylated (Nakar and Gutnik 2003). A similar phenotype was observed in Erwinia amylovora, where the overproduction of the LMW phosphatase AmsI induces a strong reduction in amylovoran synthesis (Bugert and Geider 1995). In the gram-positive bacterium $S$. pneumoniae RX1, dephosphorylation of the tyrosine kinase CpsD is essential to promote CPS synthesis (Morona et al. 2003), whereas the opposite situation was found in S. pneumoniae D39 (Bender et al. 2003). Despite contrasting results, apparently, the overall level of phosphorylation rather than phosphorylation of a particular tyrosine residue seems to account for polysaccharide polymerization, and both phosphorylated and nonphosphorylated forms of PTK seem to be required for polysaccharide synthesis (Paiment et al. 2002; Obadia et al. 2007).

A conserved PCP motif (formerly termed proline-rich motif) located in the N-terminal periplasmic domain close to the second transmembrane region was identified in PTK associated with capsule and exopolysaccharide biosynthesis. This PCP motif contains two invariant amino acid residues, alanine and proline. The proline residue was shown to affect the degree of colanic acid (P422 of $\mathrm{Wzc}_{\mathrm{ca}}$ ) and EPS I (P457 of ExoP) polymerization in E. coli $\mathrm{K} 12$ and $S$. meliloti, respectively (Becker and
Pühler 1998; Obadia et al. 2007). Furthermore, two highly conserved lysines next to the conserved proline residue and one arginine were also detected in the PCP motif in these PTK. In $S$. meliloti, substitution of this arginine residue (R443) also altered the polymerization of the EPS I (Becker and Pühler 1998).

Although the amino acid substitutions R443L and P457S in the $S$. meliloti ExoP protein resulted in a drastic reduction of the ratio of HMW EPS I in favor of LMW EPS I, the cytoplasmic localization of the C-terminal ExoP domain was not affected, as demonstrated by the activity of exoP-lacZ translational fusions (Becker and Pühler 1998). In this study, we found that these amino acid substitutions resulted in a higher level of tyrosine phosphorylation of the ExoP protein in $S$. meliloti, implying that tyrosine phosphorylation of the C-terminal ExoP domain influences EPS I polymerization in a negative fashion. However, amino acid substitution K459I, which also resulted in a drastic change in the level of tyrosine phosphorylation, produced HMW and LMW EPS I at a ratio similar to that of the wild type (Becker and Pühler 1998). These results suggest that tyrosine phosphorylation of the $\mathrm{C}$ terminal ExoP domain could be modulated by conformational changes of the N-terminal domain. Such conformational change may be mediated by protein-protein interactions. In accordance with this hypothesis, the N-terminal ExoP domain contains putative coiled-coils motifs.

Deletion of one of the predicted coiled-coil motifs from the $\mathrm{N}$-terminal ExoP domain supports this assumption. The truncated ExoP protein was not phosphorylated and this mutant neither produced EPS I nor was able to invade $M$. sativa nodules. However, localization at the inner membrane and antigenic properties of the C-terminal ExoP domain were not affected. These findings indicate that the integrity of the $\mathrm{N}$-terminal ExoP domain and, particularly, the presence of coiled-coil motifs are required for EPS I synthesis or export. Either the amount or the stability of the ExoP protein along with the extent of tyrosine phosphorylation of its C-terminal ExoP domain influence the polymerization of EPS I.

LMW EPS I is thought to be particularly important for nodule invasion (Battisti et al. 1992). Interestingly, mutants carrying the ExoP amino acid substitutions R443L and P457S, which almost exclusively produced LMW EPS I under normal culture conditions, showed different symbiotic phenotypes on $M$. sativa. Whereas mutant RmR443L induced effective pink nodules, mutant RmP457S induced both ineffective white elongated and effective pink nodules. The phenotypes of these mutants suggest that HMW EPS I is not required in a significant amount for induction of pink nodules. However, the possibility cannot be excluded that conditions within the nodule, such as high osmolarity (Jensen et al. 2005), may have altered the production of bacterial surface polysaccharides.

\section{MATERIALS AND METHODS}

\section{Bacterial strains and growth conditions.}

Bacterial strains and plasmids used in this study are listed in Table 3. Escherichia coli strains were grown in Luria-Bertani (LB) broth (Sambrook et al. 1989) at $37^{\circ} \mathrm{C}$ and S. meliloti strains in either TY (Beringer 1974) or LB supplemented with $2.5 \mathrm{mM} \mathrm{CaCl}_{2}$ and $2.5 \mathrm{mM} \mathrm{MgSO}_{4}$. For EPS I production, $S$. meliloti strains were cultured at $30^{\circ} \mathrm{C}$ in GMS medium $(\mathrm{pH}$ 7.0) supplemented with biotin, thiamine, and trace elements (Zevenhuisen and van Neerven 1983). When required, the medium also contained either $240 \mathrm{mM}$ sodium chloride or 375 $\mathrm{mM}$ sucrose.

Antibiotics were added as required at the following concentrations: for E. coli, ampicillin (Ap) at $100 \mu \mathrm{g} / \mathrm{ml}$, kanamycin $(\mathrm{Km})$ at $50 \mu \mathrm{g} / \mathrm{ml}$, gentamicin $(\mathrm{Gm})$ at $20 \mu \mathrm{g} / \mathrm{ml}$, and tetracy- 
cline (Tc) at $10 \mu \mathrm{g} / \mathrm{ml}$; and, for $S$. meliloti, spectinomycin (Sp) at $200 \mu \mathrm{g} / \mathrm{ml}$, streptomycin $(\mathrm{Sm})$ at $400 \mu \mathrm{g} / \mathrm{ml}$, nalidixic acid (Nx) at $10 \mu \mathrm{g} / \mathrm{ml}$, Tc at $8 \mu \mathrm{g} / \mathrm{ml}, \mathrm{Gm}$ at $40 \mu \mathrm{g} / \mathrm{ml}$, and neomy$\operatorname{cin}(\mathrm{Nm})$ at $120 \mu \mathrm{g} / \mathrm{ml}$.

\section{DNA and protein biochemistry.}

Preparation of plasmid DNA, DNA restriction, agarose gel electrophoresis, SDS-PAGE, cloning procedures, and transformations of $E$. coli cells were carried out according to previously described protocols (Laemmli 1970; Sambrook et al. 1989).

\section{Construction of mutants $\operatorname{Rm} \Delta \operatorname{exoP2}, \operatorname{Rm} \Delta \operatorname{exoP2/exoP*}$,

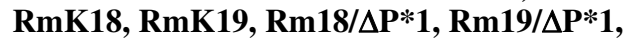 and $\operatorname{Rm} \Delta$ exoPn.}

Mutant Rm $\Delta$ exoP2 was constructed by Gene Splicing by Overlap Extension (gene SOEing), with some modifications, according to Horton (1995). The following primers were used to amplify the flanking DNA regions of exoP2 by PCR: if AAAAGAATTCGAAATACAGCGTAGAGGCGG (EcoRI restriction site underlined), 2r GGTACCCTTGCGATATTGTC GCGTCACCATTGGCGCTCTAGCAT (KpnI restriction site underlined; the region in bold corresponds to the reverse complement of primer 3f), 3f GACGCGACAATATCGCAAG

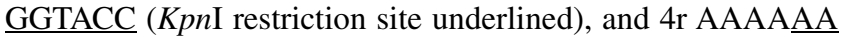
GCTTAGCGGACGTACCACGTCTAT (HindIII restriction site underlined). Primers 1 and 2 amplified a 1,000-bp DNA fragment consisting of the first $19 \mathrm{bp}$ of the exoP2 coding region plus upstream DNA. Primers 3 and 4 amplified a 1,135-bp DNA fragment consisting of the terminal $43 \mathrm{bp}$ of exoP2 plus downstream DNA. PCR products were ligated into the pGEMT Easy vector (Promega, Madison, WI, U.S.A.), resulting in plasmids p1-2 and p3-4. The inserts were recovered from plasmids p1-2 and p3-4 by restriction using EcoRI/KpnI or KpnI/HindIII, respectively. Plasmid pK18dexoP2 resulted from insertion of these fragments, joined at the KpnI site, into

Table 3. Bacterial strains and plasmids used in this study

\begin{tabular}{|c|c|c|}
\hline Strains & Relevant characteristics $^{\mathbf{a}}$ & Reference or source \\
\hline \multicolumn{3}{|l|}{ Sinorhizobium meliloti } \\
\hline Rm2011 & Wild type; $\mathrm{Nx}^{\mathrm{r}}, \mathrm{Sm}^{\mathrm{r}}$ & J. Dénarié, France \\
\hline $\mathrm{Rm} \Delta \mathrm{exoP}$ & $\begin{array}{l}\mathrm{Rm} 2011 \text { carrying a Spc }{ }^{\mathrm{r}} \text { cassette replacing the } 40-\mathrm{bp} \text { exoN } 3^{\prime} \text { portion, the intergenic region, the } \\
\text { complete exoP region, and the 262-bp downstream of exoP; } \mathrm{Sm}^{\mathrm{r}}, \mathrm{Sp}^{\mathrm{r}}\end{array}$ & Becker and Pühler 1998 \\
\hline $\mathrm{Rm} \Delta \mathrm{P}^{*} 1$ & $\begin{array}{l}\mathrm{Rm} 2011 \text { carrying a } \mathrm{Gm}^{\mathrm{r}} \text { cassette replacing the } 915-\mathrm{bp} \text { exoP } 3^{\prime} \text { portion, the intergenic region, and } \\
\text { the 85-bp thi } 3^{\prime} \text { part; } \mathrm{Sm}^{\mathrm{r}}, \mathrm{Gm}^{\mathrm{r}}\end{array}$ & Becker et al. 1995 \\
\hline RmexoP* & p18md299 integrated into the genome of $\mathrm{Rm} 2011 ; \mathrm{Sm}^{\mathrm{r}}, \mathrm{Nm}^{\mathrm{r}}$ & This work \\
\hline RmAR9007 & Rm2011, exoY-lacZ/aacC1 & Keller et al. 1995 \\
\hline 2011mTn5STM.4.05.C08 & $\mathrm{Rm} 2011$ exoP2::mini-Tn5-STM, $\mathrm{Sm}^{\mathrm{r}}, \mathrm{Nm}^{\mathrm{r}}$ & Pobigaylo et al. 2006 \\
\hline $\mathrm{Rm} \Delta \mathrm{exoP} 2$ & $\mathrm{Rm} 2011$ carrying a $\mathrm{Gm}^{\mathrm{r}}$ cassette replacing the $1837-\mathrm{bp}$ deleted from exoP $2 ; \mathrm{Sm}^{\mathrm{r}}, \mathrm{Gm}^{\mathrm{r}}$ & This work \\
\hline $\mathrm{Rm} \Delta \mathrm{exoP} 2 / \mathrm{exoP}^{*}$ & $\begin{array}{l}\text { Combination of the exoP and exoP2 mutations derived from RmexoP* and } \mathrm{Rm} \Delta \mathrm{exoP} 2 \text { in } \mathrm{Rm} 2011 \text {, } \\
\mathrm{Sm}^{\mathrm{r}}, \mathrm{Gm}^{\mathrm{r}}, \mathrm{Nm}^{\mathrm{r}}\end{array}$ & This work \\
\hline $\mathrm{Rm} 18$ & Nonpolar SMb21506 mutant in $\mathrm{Rm} 2011 ; \mathrm{Sm}^{\mathrm{r}}, \mathrm{Nm}^{\mathrm{r}}$ & This work \\
\hline $\mathrm{Rm} 19$ & Polar SMb21506 mutant in $\mathrm{Rm} 2011 ; \mathrm{Sm}^{\mathrm{r}}, \mathrm{Nm}^{\mathrm{r}}$ & This work \\
\hline $\mathrm{Rm} 18 / \Delta \mathrm{P} * 1$ & Plasmid p18Y21506 integrated into the genome of $\mathrm{Rm} \Delta \mathrm{P}^{*} 1 ; \mathrm{Sm}^{\mathrm{r}}, \mathrm{Gm}^{\mathrm{r}}, \mathrm{Nm}^{\mathrm{r}}$ & This work \\
\hline $\mathrm{Rm} 19 / \Delta \mathrm{P}^{*} 1$ & Plasmid p19Y21506 integrated into the genome of $\mathrm{Rm} \Delta \mathrm{P} * 1 ; \mathrm{Sm}^{\mathrm{r}}, \mathrm{Gm}^{\mathrm{r}}, \mathrm{Nm}^{\mathrm{r}}$ & This work \\
\hline $\mathrm{Rm} \Delta \mathrm{exoP} / \mathrm{pExoP}$ & pExoP integrated into the genome of $\mathrm{Rm} \Delta \operatorname{exoP} ; \mathrm{Sm}^{\mathrm{r}}, \mathrm{Sp}^{\mathrm{r}}, \mathrm{Nm}^{\mathrm{r}}$ & Becker and Pühler 1998 \\
\hline $\mathrm{RmR} 443 \mathrm{~L}$ & pExoP.R443L integrated into the genome of Rm $\Delta \operatorname{exoP} ; \mathrm{Sm}^{\mathrm{r}}, \mathrm{Sp}^{\mathrm{r}}, \mathrm{Nm}^{\mathrm{r}}$ & Becker and Pühler 1998 \\
\hline $\mathrm{RmP} 457 \mathrm{~S}$ & pExoP.P457S integrated into the genome of Rm $\Delta$ exoP; $\mathrm{Sm}^{\mathrm{r}}, \mathrm{Sp}^{\mathrm{r}}, \mathrm{Nm}^{\mathrm{r}}$ & Becker and Pühler 1998 \\
\hline RmK459I & pExoP.K459I integrated into the genome of Rm $\Delta$ exoP; $\mathrm{Sm}^{\mathrm{r}}, \mathrm{Sp}^{\mathrm{r}}, \mathrm{Nm}^{\mathrm{r}}$ & Becker and Pühler 1998 \\
\hline $\mathrm{Rm} \Delta \mathrm{exoPn}$ & pExoPn integrated into the genome of $\mathrm{Rm} \Delta \mathrm{exoP} ; \mathrm{Sm}^{\mathrm{r}}, \mathrm{Sp}^{\mathrm{r}}, \mathrm{Nm}^{\mathrm{r}}$ & This work \\
\hline \multicolumn{3}{|l|}{ Escherichia coli } \\
\hline DH5 $\alpha$ & endA1 recA1 hsdR17 supE44 thi-1 gyrA96 relA1 $\Delta$ (lacZYA-argF)U169 Ф80d lacZ $\Delta \mathrm{M} 15$ & Hanahan 1983 \\
\hline S17-1 & pro recA $h s d R$, thi $\mathrm{RP} 4-2-\mathrm{Tc}:: \mathrm{Mu}-\mathrm{Km}:: \mathrm{Tn} 7$ integrated into the chromosome & Simon et al. 1983 \\
\hline \multicolumn{3}{|c|}{ 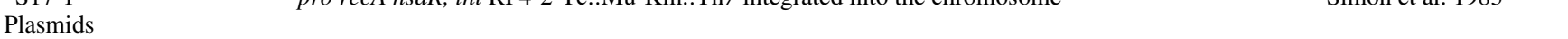 } \\
\hline pK18mob & pK18 derivative, mob-site, $\mathrm{Km}^{\mathrm{r}}$ & Schäfer et al. 1994 \\
\hline pK18mob2 & pK18mob derivative with unique $K p n I$ and $S a c I$ sites in the multiple cloning site & Tauch et al. 1998 \\
\hline pGEM-Teasy & cloning vector, $\mathrm{Ap}^{\mathrm{r}}$ & Promega \\
\hline $\mathrm{p} 1-2$ & $\begin{array}{l}\text { pGEM-Teasy derivative containing a 1,000-bp DNA fragment consisting of } 19 \mathrm{bp} \text { from the } 5^{\prime} \text { end } \\
\text { of the exoP2 coding region and upstream DNA, } \mathrm{Ap}^{\mathrm{r}}\end{array}$ & This work \\
\hline p3-4 & $\begin{array}{l}\text { pGEM-Teasy derivative containing a 1,135-bp DNA fragment consisting of } 43 \mathrm{bp} \text { from the } 3^{\prime} \text { end } \\
\text { of exoP2 and downstream DNA, Ap }\end{array}$ & This work \\
\hline pK18dexoP2 & $\begin{array}{l}\text { EcoRI-KpnI and KpnI-HindIII DNA fragments from plasmids p1-2 and p3-4, respectively, cloned } \\
\text { into the EcoRI and HindIII sites of pK18mob2, } \mathrm{Km}^{\mathrm{r}}\end{array}$ & This work \\
\hline pK18dexoP2Gm & pK18dexoP2 derivative carrying a $\mathrm{Gm}^{\mathrm{r}}$ cassette inserted in the $K p n I$ site; $\mathrm{Km}^{\mathrm{r}} \mathrm{Gm}^{\mathrm{r}}$ & This work \\
\hline p18md299 & Internal 365-bp EcoRI-HindIII fragment of exoP cloned in vector pK18mob & This work \\
\hline 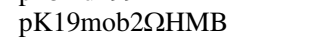 & pK19mob2 derivative with unique HindIII, BsrGI, and $M f e$ I sites followed by a terminator, $\mathrm{Km}^{\mathrm{r}}$ & Luo et al. 2005 \\
\hline p19Y21506 & 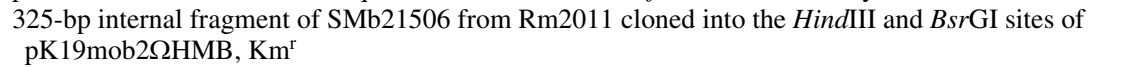 & This work \\
\hline p18Y21506 & $\begin{array}{l}\text { 325-bp internal fragment of SMb21506 from Rm2011 cloned into the EcoRI and HindIII sites of } \\
\text { pK18mob2, Km }\end{array}$ & This work \\
\hline pExoP & pK19mdGE derivative carrying the fragment deleted from the exoP-exoN region of $\mathrm{Rm} \Delta \mathrm{exoP}, \mathrm{Km}^{\mathrm{r}}$ & Becker and Pühler 1998 \\
\hline pExoPn & $\begin{array}{l}\text { pExoP derivative characterized by deletion of the 411-bp internal Pst } \mathrm{I} \text { fragment from the } 5^{\prime} \text { part of } \\
\text { exoP encoding the N-terminal ExoP, } \mathrm{Km}^{\mathrm{r}}\end{array}$ & This work \\
\hline pExoP.R443L & pExoP with a nucleotide substitution in exoP resulting in the amino acid exchange R443L, $\mathrm{Km}^{\mathrm{r}}$ & Becker and Pühler 1998 \\
\hline pExoP.P457S & pExoP with a nucleotide substitution in exoP resulting in the amino acid exchange P457S, $\mathrm{Km}^{\mathrm{r}}$ & Becker and Pühler 1998 \\
\hline pExoP.K459I & pExoP with a nucleotide substitution in exoP resulting in the amino acid exchange K459I, $\mathrm{Km}^{\mathrm{r}}$ & Becker and Pühler 1998 \\
\hline pMS255 & pSVB30 derivative containing a $1.1-\mathrm{kb}$ aac $C 1 \mathrm{Gm}^{\mathrm{r}}$ cassette; $\mathrm{Ap}^{\mathrm{r}}, \mathrm{Gm}^{\mathrm{r}}$ & Becker at al. 1995 \\
\hline \multicolumn{3}{|c|}{ 然 } \\
\hline ФМ12 & S. meliloti transducing phage & Finan et al. 1984 \\
\hline
\end{tabular}

${ }^{\mathrm{a}} \mathrm{Nx}^{\mathrm{r}}, \mathrm{Sm}^{\mathrm{r}}, \mathrm{Spc}^{\mathrm{r}}, \mathrm{Tc}^{\mathrm{r}}, \mathrm{Nm}^{\mathrm{r}}, \mathrm{Gm}^{\mathrm{r}}$, and $\mathrm{Km}^{\mathrm{r}}$ = resistant to nalidixic acid, streptomycin, spectinomycin, tetracycline, neomycin, gentamicin, and kanamycin, respectively. 
the EcoRI/HindIII-digested vector pK18mob2. Insertion of the $\mathrm{Gm}$ resistance cassette derived from plasmid pMS255 into the internal KpnI site generated plasmid pK18dexoP2Gm carrying 62-bp of exoP2 interrupted by the Gm resistance gene and flanked by upstream and downstream DNA. pK18dexoP2Gm was introduced to $S$. meliloti 2011 by E. coli S17-1 mediated conjugal transfer. Transconjugants characterized by marker exchange $(\mathrm{Rm} \Delta$ exoP2) were identified by resistance to $\mathrm{Sm}$ and $\mathrm{Gm}$ and sensitivity to $\mathrm{Nm}$. The selected $\mathrm{Rm} \Delta$ exoP2 mutant was verified by PCR amplification and sequencing of exoP2 mutant-specific fragments.

To construct double mutant $\mathrm{Rm} \Delta \mathrm{exoP} 2 / \mathrm{exoP}^{*}$, the $\Delta$ exoP2 mutation was transferred to strain $\mathrm{RmexoP}^{*}$ by phage $\Phi \mathrm{M} 12$ mediated general transduction as described by Finan and associates (1984).

Mutant $\mathrm{Rm} \Delta$ exoPn was generated by deletion of an internal 411-bp PstI fragment encoding a part of the N-terminal ExoP domain. For this purpose, the PstI fragment was deleted from plasmid pExoP, giving rise to plasmid pExoPn. Transconjugants carrying this deletion in place of the wild-type copy of exoP were obtained after conjugal transfer of this plasmid to $\mathrm{Rm} \triangle$ exoP and homologous recombination. The mutation was verified by PCR amplification and sequencing.

The nonpolar mutant Rm18 was generated by integration of plasmid p18Y21506 into the SMb21506 coding region of wild-type strain Rm2011 following E. coli S17-1-mediated conjugal plasmid transfer and homologous recombination. Transconjugants were selected for resistance to $\mathrm{Sm}$ and $\mathrm{Nm}$. Plasmid p18Y21506 carries an internal 325-bp fragment of SMb21506 that was generated by PCR amplification using the primers 21506f (AAAAGAATTCCCACGACTCGATGAGCT GCGG, EcoRI restriction site underlined) and 21506r ( $\underline{\mathrm{AAG}}$ CTTCGGATGTCGCTCGCCATAG, HindIII restriction site underlined) and subsequent insertion into the EcoRI and HindIII restriction sites of vector pK18mob2. The same strategy was applied to generate the polar mutant Rm19. The identical 325bp region of SMb21506 was amplified by PCR using primers P21506f (GGTTCCACGTAAGCTTCCACGACTCGATGAG CTGCGG, HindIII restriction site underlined) and P21506r (GCGATTACCCTGTACACCCGGATGTCGCTCGCCATAG, $B s r$ GI restriction site underlined) and inserted into the HindIII

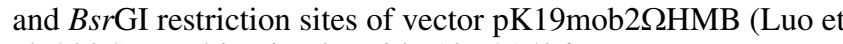
al. 2005), resulting in plasmid p19Y21506.

Double mutants $\mathrm{Rm} 18 / \Delta \mathrm{P} * 1$ and $\mathrm{Rm} 19 / \Delta \mathrm{P}^{*} 1$ were obtained by integration of plasmids p18Y21506 and p19Y21506, respectively, into the $\mathrm{SMb} 21506$ gene of mutant strain $\mathrm{Rm} \Delta \mathrm{P} * 1$. Transconjugants were selected for resistance to $\mathrm{Sm}, \mathrm{Gm}$, and $\mathrm{Nm}$.

\section{RNA purification.}

Bacterial cultures were grown to an $\mathrm{OD}_{600}$ of 0.6 in GMS medium with or without $240 \mathrm{mM} \mathrm{NaCl}(0.5$ osmol/liter $)$ or $375 \mathrm{mM}$ sucrose $(0.5 \mathrm{osmol} / \mathrm{liter})$. For RNA extraction, three independent cultures from each treatment were pooled and 1 $\mathrm{ml}$, corresponding to approximately $10^{8} \mathrm{CFU} / \mathrm{ml}$, was mixed by vortexing with $2 \mathrm{ml}$ of RNAprotect Bacteria (Qiagen, Hilden, Germany) and incubated for $5 \mathrm{~min}$ at room temperature. Total RNA was purified applying the RNeasy mini kit (Qiagen) according to the manufacturer's instructions. The RNA samples were treated with Qiagen on-column RNase-free DNase and then further purified. A second purification and concentration step was performed with the RNeasy MinElute cleanup kit (Qiagen) following the manufacturer's instructions. Integrity of RNA samples was confirmed by agarose gel electrophoresis. RNA concentration was determined in a Qubit fluorometer (Invitrogen, Carlsbad, CA, U.S.A.) by means of the Quanti-iT RNA Assay kit (Invitrogen).
qPCR.

Reverse transcription was carried out with $2 \mu \mathrm{g}$ of total RNA with AffinityScript reverse transcriptase (Stratagene, La Jolla, CA, U.S.A.), random hexamers, and oligo (dT) as primers. Gene-specific primers for SMb21506 (Q21506F: CACCTCCT GGGCAGCATC and Q21506R: GGCAACCGAAAGGACG AG), exoP2 (QexoP2F: TACAACGGATTCGATCTTCAC and QexoP2R: AGCAATCTTCTCGGACCTG), and 16S rRNA (Q16SF: TCGTGTCGTGAGATGTTG and Q16S R: ACTGTC ACCACCATTGTAG) were designed by applying the Beacon designer 7.5 software (Premier Biosoft, Palo Alto, CA, U.S.A.).

All qPCR reactions were performed in $25-\mu$ l reaction mixtures containing $2 \mu \mathrm{l}$ of cDNA, $12.5 \mu \mathrm{l}$ of Brilliant SYBR Green QPCR Master Mix, $1.25 \mu \mathrm{l}$ of each primer $(500 \mathrm{nM}), 0.375 \mu \mathrm{l}$ of Rhodamine X (from a 1:500 dilution), and nuclease-free water to $25 \mu \mathrm{l}$. Each biological replicate was run in triplicate on the Mx3005P QPCR system (Stratagene) applying the following conditions: an initial polymerase-activation step at $95^{\circ} \mathrm{C}$ for $10 \mathrm{~min}$, followed by 40 cycles at $95^{\circ} \mathrm{C}$ for $30 \mathrm{~s}, 55^{\circ} \mathrm{C}$ for $30 \mathrm{~s}$, and $72^{\circ} \mathrm{C}$ for $30 \mathrm{~s}$. No-template and minus reverse transcriptase controls were included. Melting analyses of the products were performed to confirm a single gene-specific peak and to detect primer dimer formation. The results were analyzed by means of the MxPro real-time QPCR software 4.01 (Stratagene). The reactions were run in triplicate. The relative expression of each gene was normalized to the expression of $16 \mathrm{~S}$ rRNA and the results were analyzed by the comparative critical threshold method (Pfaffl 2001).

\section{Analysis of the EPS I distribution.}

EPS I production was detected after growth of the strains on LB medium supplemented with calcofluor at $200 \mu \mathrm{g} / \mathrm{ml}$ by exposing the medium plates to UV light.

EPS I was obtained from dialyzed supernatants (molecular weight cut-off of 2,000) from 10-day-old cultures grown in GMS medium supplemented with or without either $240 \mathrm{mM}$ sodium chloride (0.5 osmol/liter) or $375 \mathrm{mM}$ sucrose $(0.5$ osmol/liter). Total carbohydrates were determined by the $\mathrm{HCl}-$ L-cysteine method (Chaplin 1986). After dialysis of the culture supernatants and lyophilization, the HMW and LMW EPS fractions were separated by gel permeation chromatography on Nucleogel columns (2× GFC 4000-8, 1× GFC 300-8, 300 by $7.7 \mathrm{~mm}$; Machery-Nagel, Düren, Germany) (flow rate, 0.8 $\mathrm{ml} / \mathrm{min}$; $200 \mathrm{mM}$ sodium chloride- $200 \mathrm{mM}$ sodium phosphate buffer, $\mathrm{pH}$ 7.0). EPS fractions were detected by using a differential refraction index detector.

\section{LPS analysis.}

LPS was prepared as described by Campbell and associates (2003). LPS were separated by $20 \%$ (wt/vol) PAGE in an SDSTricine buffer system and visualized by silver staining (Tsai and Frasch 1982).

\section{Nodulation assays.}

$S$. meliloti strains were assayed for their symbiotic phenotypes on M. sativa cv. Monarca (obtained from Instituto Nacional de Tecnología Agropecuaria, Argentina). Seed were surface sterilized and germinated as described by Müller and associates (1988). Inoculation of seedlings was carried out with log-phase cultures. The plantlets were grown on nitrogenfree medium as described by Rolfe and associates (1980) and analyzed after 3 weeks.

\section{Expression of exoP2 in $M$. sativa nodules.}

Expression of exoP2 in nodules was evaluated at 7 and 21 days after inoculation of $M$. sativa plants with exoP2 mutant strain 2011mTn5STM.4.05.C08. Roots were immersed in GUS 
buffer (50 mM sodium phosphate buffer, pH 7.0; 10 mM EDTA; $0.1 \%$ [vol/vol] Triton X-100; and $0.1 \%$ [wt/vol] sodium laurylsarcosine) containing $1 \mathrm{mM} 5$ bromo-4-chloro-3-indolyl- $\beta$-Dglucuronic acid (sodium salt) and incubated in the dark at $30^{\circ} \mathrm{C}$ for $24 \mathrm{~h}$ (Mrabet et al. 2005). Stained nodules were observed and imaged through a $\times 5$ objective lens on a Zeiss upright microscope.

\section{Cell fractionation.}

Bacteria were grown to an $\mathrm{OD}_{600}$ of 0.7 in $250 \mathrm{ml}$ of $\mathrm{TY}$ or GMS medium. Cells were harvested and resuspended to an $\mathrm{OD}_{600}$ of 2.0 in $10 \mathrm{mM}$ Tris- $\mathrm{HCl}, \mathrm{pH} 8.0$, containing $1 \mathrm{mM}$ phenylmethylsulfonyl fluoride, RNaseA $(20 \mu \mathrm{g} / \mathrm{ml})$, and DNaseI $(10 \mu \mathrm{g} / \mathrm{ml})$. Cell fractionation was performed at $4^{\circ} \mathrm{C}$. The cell suspension was lysed by two passages through a French pressure cell. After this step, intact bacteria were removed by centrifugation $(4,000 \times g$ for $10 \mathrm{~min})$. The cell-free lysate was centrifuged at $100,000 \times g$ for $1 \mathrm{~h}$, resulting in a cytosol-periplasm fraction (supernatant) and a pellet containing the cell envelopes. The latter was resuspended in $10 \mathrm{mM}$ Tris- $\mathrm{HCl}, \mathrm{pH}$ 8.0, and further separated into inner and outer membranes by solubilization with $2 \%$ (wt/vol) sarkosyl (in $10 \mathrm{mM}$ Tris- $\mathrm{HCl}, \mathrm{pH}$ 8.0) for 30 min at room temperature (Filip et al. 1973). The outer membrane is insoluble under these conditions, and was collected as a pellet by centrifugation at $100,000 \times g$ for $1 \mathrm{~h}$. Periplasmic proteins were released by treating cells with chloroform as described by Ames and associates (1984).

\section{Immunoblot analysis.}

Membrane proteins were separated by SDS-PAGE and blotted onto a nitrocellulose membrane by means of a semidry electrophoretic transfer cell, as described by Towbin and associates (1979). ExoP protein was detected with an ExoP-specific peptide antibody (rabbit) (Eurogentec, Seraing, Belgium) raised with peptide EWGRTPSRLVR. The antibody anti-ExoP was diluted in Tris-buffered saline supplemented with $0.1 \%$ (vol/vol) Tween 20 and $0.3 \%$ (wt/vol) nonfat dry milk. Binding of the secondary antibody, biotinylated anti-rabbit immunoglobulin G (GE Healthcare, Piscataway, NJ, U.S.A.), was detected with streptavidin-biotinylated horseradish peroxidase complex (GE Healthcare) and diaminobenzidine- $\mathrm{H}_{2} \mathrm{O}_{2}$ (DAB$\mathrm{H}_{2} \mathrm{O}_{2}$ ) (Sigma, St. Louis). Phosphorylation on tyrosine residues was detected with the monoclonal anti-phosphotyrosine-biotinylated antibody (clone PT-66) (Sigma). Detection was carried out by means of the streptavidin-biotinylated horseradish peroxidase complex and DAB- $\mathrm{H}_{2} \mathrm{O}_{2}$.

\section{Bioinformatics tools.}

Transmembrane and coiled coils regions were predicted by means of the program TopPredII and the algorithm COILS (window 21), respectively; available at the Expasy website. Protein alignments were carried out applying the program Clustal W.

\section{AKNOWLEDGMENTS}

This work was funded by grants $0313805 \mathrm{~A}$ from the Bundesministerium für Bildung und Forschung, Germany and PICT 32936/05 from the Agencia Nacional de Promoción Científica y Tecnológica, Argentina. E. Jofré is a member of the Research Career of the Consejo Nacional de Investigaciones Científicas y Técnicas (CONICET).

\section{LITERATURE CITED}

Aman, P., McNeil, M., Franzen, L., Darvill, A. G., and Albersheim, P. 1981. Structural elucidation using HPLC-MS and GLC-MS of the acidic polysaccharide secreted by Rhizobium meliloti strain 1021. Carbohydr. Res. 95:263-282.
Ames, G., Prody, C., and Kustu, S. 1984. Simple, rapid, and quantitative release of periplasmic proteins by chloroform. J. Bacteriol. 160:11811183.

Battisti, L., Lara, J. C., and Leigh, J. A. 1992. Specific oligosaccharide form of the Rhizobium meliloti exopolysaccharide promotes nodule invasion in alfalfa. Proc. Natl. Acad. Sci. U.S.A. 89:5625-5629.

Becker, A., and Pühler, A. 1998. Specific amino acid substitutions in the proline-rich motif of the Sinorhizobium meliloti ExoP protein result in enhanced production of low-molecular-weight succinoglycan at the expense of high-molecular-weight succinoglycan. J. Bacteriol. 180:395399.

Becker, A., Niehaus, K., and Pühler, A. 1995. Low molecular weight succinoglycan is predominantly produced by Rhizobium meliloti strains carrying a mutated ExoP protein characterized by a periplasmic N-terminal and a missing C-terminal domain. Mol. Microbiol. 16:191-203.

Bender, M. H., Cartee, R. T., and Yother, J. 2003. Positive correlation between tyrosine phosphorylation of $\mathrm{CpsD}$ and capsular polysaccharide production in Streptococcus pneumoniae. J. Bacteriol. 185:6057-6066.

Beringer, J. E. 1974. R factor transfer in Rhizobium leguminosarum. J. Gen. Microbiol. 84:188-198.

Breedveld, M. W., Zevenhuisen, L. P. T. M., and Zehnder, A. J. B. 1990. Osmotically induced oligo- and polysaccharide synthesis by Rhizobium meliloti SU47. J. Gen. Microbiol. 136:2511-2519.

Bugert, P., and Geider, K. 1995. Molecular analysis of the ams operon required for exopolysaccharide synthesis of Erwinia amylovora. Mol. Microbiol. 15:917-933.

Campbell, G. R. O., Sharypova, L. A., Scheidle, H., Jones, K. M., Niehaus, K., Becker, A., and Walker, G. C. 2003. Striking complexity of lipopolysaccharide defects in a collection of Sinorhizobium meliloti mutants. J. Bacteriol. 185:3853-3862.

Chaplin, M. F. 1986. Reducing sugar-neocuprine assay. Page 3 in: Carbohydrate Analysis-A Practical Approach. M. F. Chaplin and J. F. Kennedy, eds. IRL, Oxford, U.K..

Cozzone, A. J., Grangeasse, C., Doublet, P., and Duclos, B. 2004. Protein phosphorylation on tyrosine in bacteria. Arch. Microbiol. 181:171-181. Domínguez-Ferreras, A., Pérez-Arnedo, R., Becker, A., Olivares, J., Soto, M. J., and Sanjuán, J. 2006. Transcriptome profiling reveals the importance of plasmid pSymB for osmoadaptation of Sinorhizobium meliloti. J. Bacteriol. 188:7617-7625.

Doublet, P., Vincent, C., Grangeasse, A. J., Cozzone, B., and Duclos, B. 1999. On the binding of ATP to the autophosphorylating protein, Ptk, of the bacterium Acinetobacter johnsonii. FEBS (Fed. Eur. Biochem. Soc.) Lett. 445:137-143.

Filip, C., Fletcher, G., Wulff, J. L., and Earhart, C. F. 1973. Solubilization of the cytoplasmic membrane of Escherichia coli by the ionic detergent sodium-lauryl sarcosinate. J. Bacteriol. 115:717-722.

Finan, T. M., Hartwieg, E., LeMieux, K., Bergman, K., Walker, G. C., and Signer, E. R. 1984. General transduction in Rhizobium meliloti. J. Bacteriol. 159:120-124.

Glucksmann, M. A., Reuber, T. L., and Walker, G. C. 1993. Genes needed for the modification, polymerization, export, and processing of succinoglycan by Rhizobium meliloti: a model for succinoglycan biosynthesis. J. Bacteriol. 175:7045-7055.

González, J. E., Semino, C. E., Wang, L., Castellano-Torres, L. E., and Walker, G. C. 1998. Biosynthetic control of molecular weight in the polymerization of the octasaccharide subunits of succinoglycan, a symbiotically important exopolysaccharide of Rhizobium meliloti. Proc. Natl. Acad. Sci. U.S.A. 95:13477-13482.

Grangeasse, C., Doublet, P., and Cozzone, A. J. 2002. Tyrosine phosphorylation of protein kinase Wzc from Escherichia coli K12 occurs through a two-step process. J. Biol. Chem. 277:7127-7135.

Hanahan, D. 1983. Studies on transformation of Escherichia coli with plasmids. J. Mol. Biol. 166:557-580.

Horton, R. M. 1995. PCR-mediated recombination and mutagenesis. SOEing together tailor-made genes. Mol. Biotechnol. 3:93-99.

Ilan, O., Bloch, Y., Frankel, G., Ullrich, H., Geider, K., and Rosenshine, I. 1999. Protein tyrosine kinases in bacterial pathogens are associated with virulence and production of exopolysaccharide. EMBO (Eur. Mol. Biol. Organ.) J. 18:3241-3248.

Jensen, J. B., Ampomah, O. Y., Darrah, R., Peters, N. K., and Bhuvaneswari, T. V. 2005. Role of trehalose transport and utilization in Sinorhizobium meliloti-alfalfa interactions. Mol. Plant-Microbe Interact. 18:694-702

Keller, M., Roxlau, A., Weng, W.M., Schmidt, M., Quandt, J., Niehaus, K. Jording, D., Arnold, W., and Puhler, A. 1995. Molecular analysis of the Rhizobium meliloti mucR gene regulating the biosynthesis of the exopolysaccharides succinoglycan and galactoglucan. Mol. Plant-Microbe Interact. 8:267-277.

Laemmli, U. K. 1970. Cleavage of structural proteins during the assembly of the head of bacteriophage T4. Nature 227:680-685.

Lloret, J., Bolaños, L., Lucas, M. M., Peart, J. M., Brewin, N. J., Bonilla, 
I., and Rivilla, R. 1995. Ionic stress and osmotic pressure induce different alterations in the lipopolysaccharide of a Rhizobium meliloti strain. Appl. Environ. Microbiol. 61:3701-3704.

Lloret, J., Wulff, B. B. H., Rubio, J. M., Downie, J. A., Bonilla, I., and Rivilla, R. 1998. Exopolysaccharide II production is regulated by salt in the halotolerant strain Rhizobium meliloti EFB1. Appl. Environ. Microbiol. 64:1024-1028.

Luo, L., Yao, S. Y., Becker, A., Rüberg, S., Yu, G. Q., Zhu, J.B., and Cheng, H. P. 2005. Two new Sinorhizobium meliloti LysR-type transcriptional regulators required for nodulation. J. Bacteriol. 187:4562-4572.

Lupas, A., Van Dyke, M., and Stock, J. 1991. Predicting coiled coils from protein sequences. Science 252:1162-1164.

Morona, J. K., Morona, R., Miller, D. C., and Paton, J. C. 2003. Mutational analysis of the carboxy-terminal $(\mathrm{YGX})_{4}$ repeat domain of $\mathrm{CpsD}$, an autophosphorylating tyrosine kinase required for capsule biosynthesis in Streptococcus pneumoniae. J. Bacteriol. 185:3009-3019.

Morona, R., Van Den Bosch, L., and Daniels, C. 2000. Evaluation of Wzz/MPA1/MPA2 proteins based on the presence of coiled-coil regions. Microbiology 146:1-4

Mrabet, M., Mhamdi, R., Tajini, F., Tiwari, R., Trabelsi, M., and Aouani, M. E. 2005. Competitiveness and symbiotic effectiveness of a $R$. gallicum strain isolated from root nodules of Phaseolus vulgaris. Eur. J. Agron. 22:209-221

Müller, P., Hynes, M., Kapp, D., Niehaus, K., and Pühler, A. 1988. Two classes of Rhizobium meliloti infection mutants differ in exopolysaccharide production and in coinoculation properties with nodulation mutants. Mol. Gen. Genet. 211:17-26.

Nakar, D., and Gutnick, D. L. 2003. Involvement of a protein tyrosine kinase in production of the polymeric bioemulsifier emulsion from the oil-degrading strain Acinetobacter lwoffii RAG-1. J. Bacteriol. 185:1001-1009.

Niemeyer, D., and Becker, A. 2001. The molecular weight distribution of succinoglycan produced by Sinorhizobium meliloti is influenced by specific tyrosine phosphorylation and ATPase activity of the cytoplasmic domain of the ExoP protein. J. Bacteriol. 183:5163-5170.

Obadia, B., Lacour, S., Doublet, P., Baubichon-Cortay, H., Cozzone, A. J., and Grangeasse, C. 2007. Influence of tyrosine-kinase Wzc activity on colanic acid production in Escherichia coli K12 cells. J. Mol. Biol. 367:42-53.

Paiment, A., Hocking, J., and Whitfield, C. 2002. Impact of phosphorylation of specific residues in the tyrosine autokinase, Wzc, on its activity in assembly of group 1 capsules in Escherichia coli. J. Bacteriol. 184:6437-6447.

Pfaffl, M. W. 2001. A new mathematical model for relative quantification in real-time RT-PCR. Nucleic Acids Res. 29:e45.

Pobigaylo, N., Wetter, D., Szymczak, S., Schiller, U., Kurtz, S., Meyer, F., Nattkemper, T. W., and Becker, A. 2006. Construction of a large signature-tagged mini-Tn5 transposon library and its application to mutagenesis of Sinorhizobium meliloti. Appl. Environ. Microbiol. 72:4329 4337.

Reinhold, B. B., Chan, S. Y., Reuber, T. L., Marra, A., Walker, G. C., and Reinhold, V. N. 1994. Detailed structural characterization of succinoglycan, the major exopolysaccharide of Rhizobium meliloti Rm1021. J. Bacteriol. 176:1997-2002.

Reuber, T. L., and Walker, G. C. 1993. Biosynthesis of succinoglycan, a symbiotically important exopolysaccharide of Rhizobium meliloti. Cell 74:269-280.

Rolfe, B. G., Gresshoff, P. M., and Shine, J. 1980. Rapid screening for symbiotic mutants of Rhizobium and white clover. Plant Sci. Lett. 19:277-284.
Rüberg, S., Tian, Z.-X., Krol, E., Linke, B., Meyer, F., Wang, Y., Pühler, A., Weidner, S., and Becker, A. 2003. Construction and validation of a Sinorhizobium meliloti whole genome DNA microarray: genome-wide profiling of osmoadaptive gene expression. J. Biotechnol. 106:255-268.

Sambrook, J., Fritsch, E. F., and Maniatis, T. 1989. Molecular Cloning: A Laboratory Manual, 2nd ed. Cold Spring Harbor Laboratory Press, Cold Spring Harbor, NY, U.S.A.

Schäfer, A., Tauch, A., Jäger, W., Kalinowski, J., Thierbach, G., and Pühler, A. 1994. Small mobilizable multi-purpose cloning vectors derived from the Escherichia coli plasmids pK18 and pK19: selection of defined deletions in the chromosome of Corynebacterium glutamicum. Gene 145:69-73.

Simon, R., Priefer, U., and Pühler, A. 1983. A broad host range mobilization system for in vivo genetic engineering: transposon mutagenesis in Gram-negative bacteria. Bio/Technology 1:784-791.

Skorupska, A., Janczarek, M., Marczak, M., Mazur, A., and Król, J. 2006. Rhizobial exopolysaccharides: genetic control and symbiotic functions. Microb. Cell Fact. 5:7-25.

Soussi, M., Santamaría, M., Ocaña, A., and Lluch, C. 2001. Effects of salinity on protein and lipopolysaccharide pattern in a salt-tolerant strain of Mesorhizobium ciceri. J. Appl. Microbiol. 90:476-481.

Tauch, A., Zheng, Z., Pühler, A., and Kalinowski, J. 1998. Corynebacterium striatum chloramphenicol resistance transposon Tn5564: Genetic organization and transposition in Corynebacterium glutamicum. Plasmid 40:126-139.

Towbin, H., Staehelin, T., and Gordon, J. 1979. Electrophoretic transfer of proteins from polyacrylamide gels to nitrocellulose sheets: procedure and some applications. Proc. Natl. Acad. Sci. U.S.A. 76:4350-4354.

Tsai, C., and Frasch, E. 1982. A sensitive silver stain for detecting lipopolysaccharides in polyacrylamide gels. Anal. Biochem. 119:115-119.

Vincent, C., Duclos, B., Grangeasse, C., Vaganay, E., Riberty, M., Cozzone, A. J., and Doublet, P. 2000. Relationship between exopolysaccharide production and protein-tyrosine phosphorylation in gram-negative bacteria. J. Mol. Biol. 304:311-321.

Vriezen, J. A. C., de Bruijn, F. J., and Nüsslein, K. 2007. Responses of rhizobia to desiccation in relation to osmotic stress, oxygen, and temperature. Appl. Environ. Microbiol. 73:3451-3459.

Wang, L., Wang, Y., Pellock, B., and Walker, G. C. 1999. Structural characterization of the symbiotically important low-molecular-weight succinoglycan of Sinorhizobium meliloti. J. Bacteriol. 181:6788-6796.

Wugeditsch, T., Paiment, A., Hocking, J., Drummelsmith, J., Forrester, C., and Whitfield, C. 2001. Phosphorylation of Wzc, a tyrosine autokinase, is essential for assembly of group 1 capsular polysaccharides in Escherichia coli. J. Biol. Chem. 276:2361-2371.

York, G. M., and Walker, G. C. 1998. The succinyl and acetyl modifications of succinoglycan influence susceptibility of succinoglycan to cleavage by the Rhizobium meliloti glycanases ExoK and ExsH. J. Bacteriol. 180:4184-4191.

Zahran, H. H. 1999. Rhizobium-legume symbiosis and nitrogen fixation under severe conditions and in an arid climate. Microbiol. Mol. Biol. Rev. 63:968-989.

Zevenhuisen, L. P. T. M., and van Neerven, A. R. W. 1983. (1,2)- $\beta$-D-Glucan and acidic oligosaccharides produced by Rhizobium meliloti. Carbohydr. Res. 118:127-134.

\section{AUTHOR-RECOMMENDED INTERNET RESOURCE}

ExPASy (Expert Protein Analysis System) proteomics server: www.expasy.ch 